\title{
International Risk Sharing During the Globalization Era
}

\author{
Robert P. Flood, Nancy P. Marion and \\ Akito Matsumoto
}




\title{
IMF Working Paper
}

\author{
Research Department
}

\section{International Risk Sharing During the Globalization Era}

\author{
Prepared by Robert P. Flood, Nancy P. Marion and Akito Matsumoto ${ }^{1}$
}

Authorized for distribution by Stijn Claessens

September 2009

\begin{abstract}
This Working Paper should not be reported as representing the views of the IMF. The views expressed in this Working Paper are those of the author(s) and do not necessarily represent those of the IMF or IMF policy. Working Papers describe research in progress by the author(s) and are published to elicit comments and to further debate.
\end{abstract}

Though theory suggests financial globalization should improve international risk sharing, empirical support has been limited. We develop a simple welfare-based measure that captures how far countries are from the ideal of perfect risk sharing. We then take it to data and find international risk sharing has, indeed, improved during globalization. Improved risk sharing comes mostly from the convergence in rates of consumption growth among countries rather than from synchronization of consumption at the business cycle frequency. Our finding explains why many existing measures fail to detect improved risk sharing - they focus only on risk sharing at the business cycle frequency.

JEL Classification Numbers:F4, E2, D6

Keywords: International risk sharing; incomplete market, globalization

Author's E-Mail Address: rflood1@,nd.edu; nancy.p.marion@dartmouth.edu and amatsumoto@,imf.org

\footnotetext{
${ }^{1}$ We thank Stijn Claessens, Mick Devereux, Charles Engel, Pat Kehoe, Tim Kehoe, Karen Lewis, Ellen McGrattan, Enrique Mendoza, Fabrizio Perri, Kenneth Rogoff, seminar participants at Banco Central de Chile, Midwest Macro Meetings, NBER IFM Summer Institute, NCSU, Notre Dame, Oberlin, Vanderbilt, and our colleagues at the IMF for helpful discussion. We thank Cigdem Akin and Jelena Kmezic for excellent research assistance. The views expressed in this Working Paper are those of the authors and do not necessarily represent those of the IMF or IMF policy.
} 
I. Introduction .3

II. Theory ..... 4

III. Existing Measures of International Risk Sharing ....................................................6

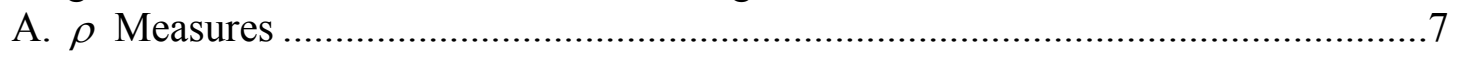

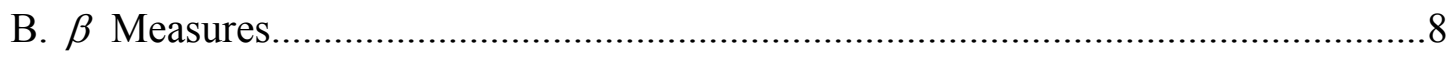

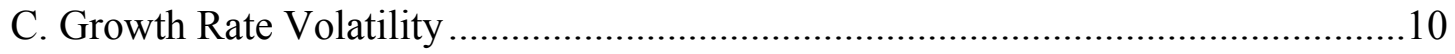

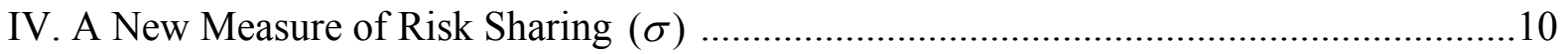

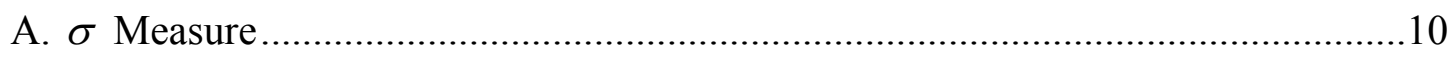

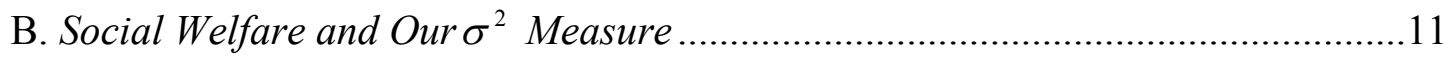

C. Frequency Decomposition............................................................................ 12

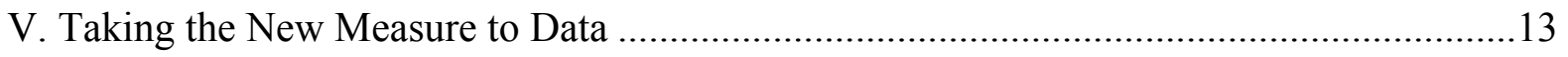

A. Results and Comparison with Existing Measures........................................... 14

B. Results of High-Low Frequency Decomposition.............................................15

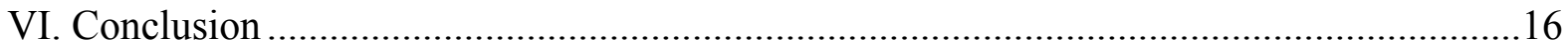

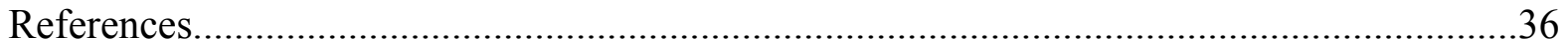

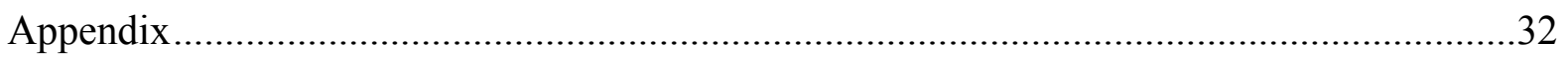

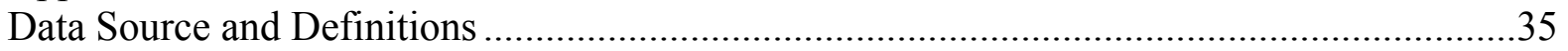

Figures

1. Lack of Perfect Risk Sharing Due to Difference in Trend Growth and Deviation from Trend........................................................................................ 17

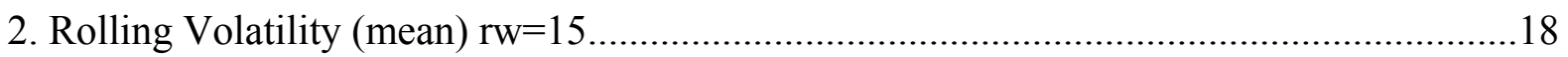

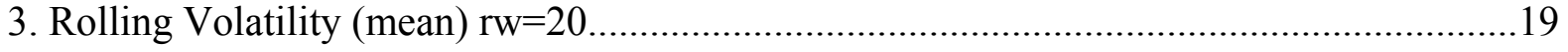

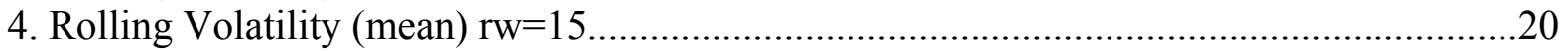

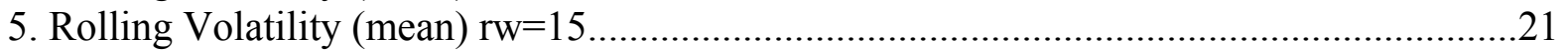

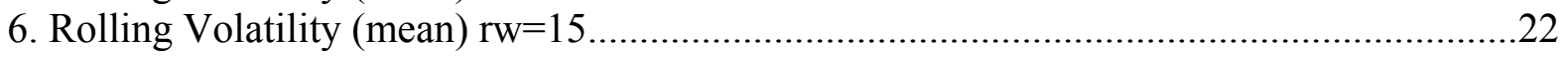

7. Relation Between the Degree of Risk Sharing and National Income in 2003...................23

8. Relation Between the Degree of Risk Sharing and National Income in 1964....................24

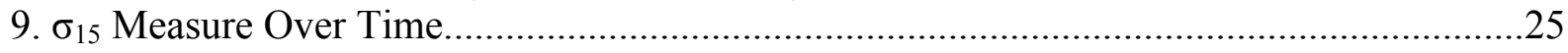

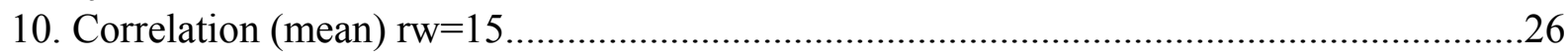

11. Correlation Measure Over Time 15-year rolling .......................................................27

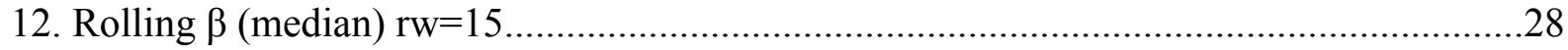

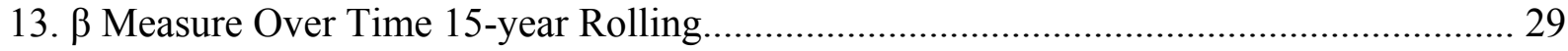

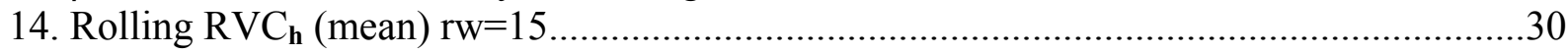

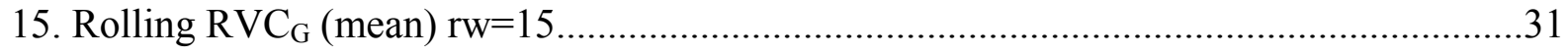




\section{INTRODUCTION}

In theory, globalization should enhance risk sharing by making it easier for individuals to diversify insurable risks - those that are minimized by sharing in large groups. Residents of different countries get the opportunity to trade financial assets and insure themselves against country-specific risks that affect the amount of goods and services they consume. ${ }^{2}$ But standard tests of risk sharing suggest that these risks are still shared imperfectly. More surprisingly, existing measures derived from these tests suggest that globalization has not improved the degree of international risk sharing. ${ }^{3} \mathrm{We}$ reassess these measures while acknowledging the results of hypothesis tests that reject perfect consumption risk sharing. Then, we develop a new welfare-based measure that differs from existing (test-derivative) measures of risk sharing. Our measure indicates that international risk sharing has been improving over time, a finding consistent with theory and intuition.

Existing methods are well designed to test the null hypothesis of perfect risk sharing, but they are poorly suited to gauge the degree of international risk sharing once the null is rejected. ${ }^{4}$ In contrast, our new measure is designed to assess how well a country shares risk and how that risk sharing has evolved under imperfect risk sharing

Our new measure is defined as the variance of the log share of individual-country per capita consumption in world per capita consumption. Under perfect risk sharing, this variance is zero. Moreover, the bigger the variance, the farther a country is from perfect risk sharing. The variance is a monotonic transformation of a simple social welfare function that is valid even under imperfect risk sharing. ${ }^{5}$ Existing test-derivative measures do not provide a rigorous link between the degree of risk sharing and the values of measures except for the perfect risk-sharing case.

Lucas (1987) observed that the welfare gain from slightly higher average output growth can make up for the welfare loss from small increases in business-cycle fluctuations. In the context of international risk sharing, the convergence of average consumption growth across countries is far more important than insuring consumption at the business cycle frequency. ${ }^{6}$

\footnotetext{
${ }^{2}$ For a review of empirical work, see Kose, Prasad, Rogoff, and Wei (2006), Corcoran (2007), and Kose, Prasad, and Terrones (2007). For the growth effect of global financial integration, see Obstfeld (1994a), who builds a model where global diversification enhances growth in a small open economy.

${ }^{3}$ For the G7, OECD, and EU, there is some limited evidence of improved risk sharing. See Obstfeld (1994b), Sorensen, Wu, Yosha, and Zhu(2007).

${ }^{4}$ Our measure is not a test of perfect risk sharing; rather, it assesses the degree of (imperfect) risk sharing. We use the words "test" and "measure" to distinguish two different concepts.

${ }^{5}$ We elaborate in Section II and IV. B. .

${ }^{6}$ Becker and Hoffmann (2006) and Artis and Hoffmann $(2006,2007)$ are among the few emphasizing long-run risk sharing. van Wincoop (1999) addresses this point as well. He shows that gains from international risk sharing are small if countries' growth rates are cointegrated and big if they are random walks. Aguiar and Gopinath (2007) find
} 
Existing risk-sharing measures generally ignore the role of average consumption growth rates. Our new measure does not. While risks can be shared through income transfers by trading assets or writing insurance contracts, these are not the only possible methods for risk sharing. Our measure is designed to capture previously ignored aspects of risk sharing achieved (perhaps) through technology transfer rather than income transfer. Our measure is sufficiently flexible that we can use it to break down risk sharing at different frequencies.

Taking the new measure to data, we find that international risk sharing has improved during the globalization period for industrial countries and, to a lesser extent, for emerging markets. The improvement, however, shows up in terms of convergence of consumption growth rates among countries, not in terms of short-term consumption smoothing at the business-cycle frequency. We also find that risks from consumption growth differences are about twice the size of business-cycle-frequency risks for both industrial countries and emerging markets. Convergence of these growth differences since 1965 has been dramatic for industrial countries. Emerging markets have poorer risk sharing than industrial countries and have shown improvement only over the last 10 years of our 1960-2004 sample.

The rest of the paper is organized as follows. In Section II, we present the basic theory of international risk sharing and derive some implications of that theory that guide us in constructing our measure. Section III reviews two existing measures of international risk sharing and explains why they have been unable to uncover improved risk sharing under globalization. In Section IV, we present our new measure and relate it to agents' welfare. Section $\mathrm{V}$ takes our new measure to data and shows how international risk sharing has evolved over the 1960-2004 period. Section VI concludes.

\section{THEORY}

Let $C_{t}^{i}$ be the date $t$ consumption of country $i$ 's representative individual. The individual maximizes the following objective function:

$$
\mathrm{E}_{0} \sum_{t=1}^{\infty} \beta^{t} \mathrm{u}\left(C_{t}^{i} \theta_{t}^{i}\right)
$$

where $\theta_{t}^{i}$ are elements other than consumption that affect individual $i$ 's utility. ${ }^{7}$ The specification is standard and we assume identical utility functions, $\mathrm{u}$, and discount factors for all agents. Let

\footnotetext{
that shocks to trend growth rather than transitory shocks are the primary source of fluctuations in emerging markets.

${ }^{7}$ For example, these elements could be preference shocks or leisure. See Obstfeld (1994b) and Canova and Ravn (1996).
} 
$\mathrm{u}\left(C_{t}^{i}, \theta_{t}^{i}\right)=\frac{C_{t}^{i^{1-\gamma}}}{1-\gamma} \exp \left(\theta_{t}^{i}\right)$. Optimal risk sharing, which can be achieved if there is a full set of Arrow-Debreu securities, implies

$$
\left(\frac{C_{t}^{i}}{C_{t}^{j}}\right)^{-\gamma} \exp \left(\theta_{t}^{i}-\theta_{t}^{j}\right)=k^{i j}, \forall t
$$

or, taking logs,

$$
\ln C_{t}^{i}-\ln C_{t}^{j}=\kappa^{i j}+\frac{\theta_{t}^{i}}{\gamma}-\frac{\theta_{t}^{j}}{\gamma}
$$

where $k^{i j}$ and $\kappa^{i j}=-\frac{1}{\gamma} \ln k^{i j}$ are constants that depend on initial wealth or the weights a social planner might attach to the utility of the agent in a country. ${ }^{8}$ If we assume that $\theta_{t}^{i}$ and $\theta_{t}^{j}$ are constants, then equation (2) implies that the consumption ratio between any two countries is constant over time when there is perfect risk sharing.

Two implications follow. ${ }^{9}$ The most widely studied one is that consumption growth rates are equalized across countries under perfect risk sharing. This relationship, holding for any country pair, holds equally well for any one country relative to the rest of the world. ${ }^{10}$ When this relationship fails to hold in data, the null of perfect risk sharing is rejected. But rejection does not yield information on how far countries are from perfect risk sharing. Another implication is that under perfect risk sharing, a country's per capita consumption is a fixed share of average world per capita consumption. Further, since this share is constant, its variance is zero. By exploiting the relationship between the sample variance and agents' welfare, we obtain a measure that is a good gauge of the degree of international risk sharing among countries when risk sharing is far from perfect. After reviewing the weakness of existing measures under imperfect risk sharing, we explain our measure and show the link between our measure and welfare under imperfect risk sharing.

\footnotetext{
${ }^{8}$ See Lewis (1996).

${ }^{9}$ These implications are derived for an idealized frictionless economy in which there are no trading frictions and hence no nontraded goods and no price rigidities causing real exchange-rate misalignments. Agents have identical time separable preferences over the consumption good. Though individual agents can potentially receive idiosyncratic preference shocks, following the literature, we ignore these preference shocks since we cannot measure them. While our assumptions are strong, we do not use them to set up a straw man to be knocked aside easily. The strong assumptions suggest a simple risk sharing measure that is easy to compute and easy to understand.

${ }^{10}$ These implications are standard in the literature based on CES utility. The implications would not necessarily follow for other utility functions where marginal utility of consumption does not have constant elasticity, e.g., quadratic utility.
} 


\section{EXISTING MEASURES OF INTERNATIONAL RISK SHARING}

The existing empirical literature on consumption risk sharing follows from the theoretical observation that if countries share risks perfectly, their consumption ratios will be constant and a country's share in world consumption will be constant also. Perfect risk sharing also implies consumption growth rates will be equal across countries. Deviations from constant consumption ratios or differences in consumption growth rates - both supposedly zero - should be uncorrelated with other variables such as incomes.

The empirical literature on international consumption risk sharing was launched when Backus, Kehoe and Kydland (1992) documented the "consumption correlation puzzle," the finding that international consumption correlations are lower than international output correlations. Obstfeld (1994b, 1995) confirmed the puzzle, but unlike many subsequent studies, found evidence of increasing consumption correlations after 1973 among industrial countries. ${ }^{11}$ Tesar and Stockman(1995) offered some possible reasons for the puzzle, such as the presence of preference shocks, and pointed out that if the empirical puzzle held up to scrutiny, it implied that agents were using international financial markets to destabilize consumption. Lewis (1996) did regression tests confirming that consumption risk sharing is imperfect, laying the blame on non-traded goods and capital controls. ${ }^{12}$

Following these seminal papers, the empirical literature extended and studied the relationships between countries' consumptions and their incomes. The literature focused primarily on two types of measures, correlation measures, which we call $\rho$ measures, and regression measures, which we call $\beta$ measures. The $\rho$ measures normally come from computing correlation coefficients of cross-country consumption aggregates measured in (detrended) levels or growth rates. It is thought such correlations should be unity when risks are shared perfectly. The $\beta$ measures are usually obtained from regressing consumption growth rates on idiosyncratic output growth and/or other things such as world consumption growth rates. The $\beta$ coefficient attached to world consumption growth should be unity and that attached to idiosyncratic output growth should be zero when risks are shared perfectly, as idiosyncratic shocks should not affect consumption growth.

Once the null of perfect risk sharing is rejected, existing measures have two potential problems. First, it is difficult to attach an economic interpretation to correlation/regression coefficients that differ from unity. Second, even if the correlation of consumption growth rates between two countries is unity, or the time-series regression coefficient on idiosyncratic output growth is zero, risk sharing need not be perfect. Sample averages of growth rates could differ across countries that are not sharing risk perfectly. Yet that possibility is not taken into account by some existing measures since growth rates among countries are assumed to be identical under the null of perfect risk sharing.

\footnotetext{
${ }^{11}$ Obstfeld (1986) also finds that international capital markets are more integrated after 1973.

${ }^{12}$ Canova and Ravn (1997) claim that short run risk insurance is almost complete among pairs of industrial countries while medium to long run risk insurance is not.
} 


\section{A. $\rho$ Measures}

Correlation measures are studied by Devereux, Gregory, and Smith (1992), Obstfeld (1994,1995), Canova and Ravn (1997), Pakko (1998), ${ }^{13}$ Heathcote and Perri (2003), Ambler, Cardia and Zimmerman (2004), and Kose, Prasad and Terrones (KPT) (2003a), among others. If consumption risks are insured perfectly, the ratio of individual-country consumption to world consumption is constant and the correlation coefficient between any two consumption-growth measures, therefore, should be unity. If the correlation coefficient between any two countries' consumption growth rates turns out to be significantly different from unity, then that is a rejection of perfect risk sharing between those two aggregates.

The above-mentioned studies almost uniformly find individual- country consumption growth to be imperfectly correlated with world consumption growth. KPT, for example, find the correlation between average industrial country consumption growth and world consumption growth to be 0.45 with a standard error of 0.06 - economically and statistically well below unity. For developing countries, KPT find the correlation to be even lower, 0.02 with a standard error of 0.04 .

While studying consumption growth correlations allows one to construct a logical test for perfect risk sharing, the correlation coefficients themselves are not a particularly good vehicle for measuring the deviation of a particular country from perfect risk sharing either at a point in time or over time. The reason can be illustrated in an example as follows.

Suppose $\log$ consumptions of the world $(W)$ and country $i$ are following random processes:

$$
\begin{aligned}
& \ln C_{W, t}=g_{1}+\ln C_{W, t-1}+\varepsilon_{t} \\
& \ln C_{i, t}=g_{2}+\ln C_{i, t-1}+\lambda \varepsilon_{t}
\end{aligned}
$$

where $g_{1}, g_{2}$ and $\lambda$ are positive constants, and $\varepsilon_{t}$ is a mean zero iid shock.

If $g_{1} \neq g_{2}$, then the ratio of country $i$ 's consumption to world consumption changes over time. The correlation measure based on consumption growth rates, however, wrongly suggests perfect risk sharing. The correlation is:

$$
\rho\left(\Delta \ln C_{W, t}, \Delta \ln C_{i, t}\right)=\frac{\operatorname{cov}\left(\varepsilon_{t}, \lambda \varepsilon_{t}\right)}{\sqrt{\operatorname{var}\left(\varepsilon_{t}\right)}, \sqrt{\operatorname{var}\left(\lambda \varepsilon_{t}\right)}}=1,
$$

\footnotetext{
${ }^{13}$ Pakko (1998) casts doubt on the reliability of the correlation measure since the empirical results change with a different detrending method. See Lewis (1996) and Matsumoto (2007) on how nontraded goods and nonseparability can affect correlations under perfect risk sharing.
} 
which ignores the difference in growth rates. The measure also ignores possible differences in the size of shocks in each period - the $\lambda^{\prime} s$ cancel in equation (5). ${ }^{14}$

\section{B. $\beta$ Measures}

Another way to study risk sharing is with regression methods. Obstfeld (1994b, 1995), for example, estimates variants of the following equation:

$$
\Delta \ln \mathrm{C}_{\mathrm{it}}=\beta_{0}^{i}+\beta_{1}^{i} \Delta \ln \mathrm{C}_{\mathrm{Wt}}+\beta_{2}^{i} \Delta \ln \mathrm{GDP}_{\mathrm{it}}+\varepsilon_{\mathrm{it}},
$$

where $\Delta \ln \mathrm{C}_{\mathrm{it}}$ is the growth of country $i$ per-capita consumption (from period $t-1$ to $t$ ), $\Delta \ln \mathrm{C}_{\mathrm{Wt}}$ is the growth rate of per-capita world consunope didmption, and $\Delta \ln \mathrm{GDP}_{\text {it }}$ is the growth rate of country i per-capita output; $\varepsilon_{i, t}$ is a residual. If risk sharing is perfect, $\beta_{1}^{i}=1$ and $\beta_{0}^{i}=\beta_{2}^{i}=\sigma_{\varepsilon}^{2}=0$, where $\sigma_{\varepsilon}^{2}$ is the variance of $\varepsilon$. Breaking his data into two periods, 1951-72 and 1973-88, Obstfeld finds that low estimates of $\beta_{1}^{i}$ and high values of $\beta_{2}^{i}$ lead to a rejection of perfect risk sharing in the 1951-1972 period for industrial countries. Yet he cannot reject perfect risk sharing for industrial countries based on the estimates obtained in the 1973-1988 period.

Obstfeld's results seem to suggest that risk sharing may have improved between the two periods. However, his results do not settle the question of improved risk sharing since the variance of the output-growth regressor may have risen and/or $\sigma_{\varepsilon}^{2}$ might have risen between the two periods. ${ }^{15}$ In addition, the difference in average consumption growth rates between an individual country and the world could be captured by $\beta_{0}^{i}$.

Kalemli-Ozcan, Sorensen, and Yosha (2003) and Sorensen et al. (2007) interpret the $\beta$ coefficient from the following panel regression as the degree of consumption risk sharing among a group of areas in the panel. ${ }^{16}$ The regression specification is

\footnotetext{
${ }^{14}$ Even if $g_{1}=g_{2}$ in (4), our measure will not conclude that country $i$ is sharing risk perfectly unless $\lambda$ is unity, as we show below.
}

\footnotetext{
${ }^{15}$ Both factors could contribute to an increase, or at least to no decrease, in the variance of the ratio $\ln \left(C_{i, t} / C_{w, t}\right)$, the measure of international risk sharing we introduce below.

${ }^{16}$ Lewis (1996) used this specification to test for complete risk sharing, which requires $\beta=1$. With perfect risk sharing, a country's idiosyncratic consumption growth should be uncorrelated with its idiosyncratic output growth. Bai and Zhang (2005) also study risk sharing using a cross-section variant.
} 


$$
\Delta \ln \mathrm{C}_{\mathrm{i}, \mathrm{t}}-\Delta \ln \mathrm{C}_{\mathrm{W}, \mathrm{t}}=f_{t}+\left(1-\beta_{t}\right)\left(\Delta \ln \mathrm{GDP}_{\mathrm{i}, \mathrm{t}}-\Delta \ln \mathrm{GDP}_{\mathrm{W}, \mathrm{t}}\right)+\varepsilon_{\mathrm{i}, \mathrm{t}},
$$

where $\Delta \ln \mathrm{GDP}_{\mathrm{i}, \mathrm{t}}$ and $\Delta \ln \mathrm{GDP}_{\mathrm{W}, \mathrm{t}}$ are the per capita GDP growth rates of area $i$ and the world respectively, $\mathrm{C}_{\mathrm{i}, \mathrm{t}}$ is consumption, and $f_{t}$ are time fixed effects. Unlike regressions with country-specific constants, this particular specification guarantees that when $\beta_{t}$ is unity, risk sharing is perfect. That said, this specification is more appropriate for a group of countries; it cannot be used to measure how well each individual country shares risk with another or with the world as a whole. In addition, the interpretation of $\beta_{t}$ is difficult when it is different from unity since risk sharing can be achieved before production takes place. Suppose a country comes up with a great technology and shares it with other countries as part of a risk sharing arrangement. This reduces the variance of idiosyncratic GDP growth rates relative to no technology transfer. However, because

$$
1-\beta_{t}=\operatorname{cov}\left(\Delta \ln \mathrm{C}_{\mathrm{it}}-\Delta \ln \mathrm{C}_{\mathrm{Wt}}, \Delta \ln \mathrm{GDP}_{\mathrm{it}}-\Delta \ln \mathrm{GDP}_{\mathrm{Wt}}\right) / \operatorname{var}\left(\Delta \ln \mathrm{GDP}_{\mathrm{it}}-\Delta \ln \mathrm{GDP}_{\mathrm{Wt}}\right),
$$

a risk-sharing arrangement with technology transfer may reduce $\beta_{t}$ through a smaller

denominator. Therefore, unless GDP growth is not affected by risk sharing, a small $\beta_{t}$ does not necessarily mean poorer risk sharing.

Kose et al. (2007) run a time series regression of similar form:

$$
\Delta \ln \mathrm{C}_{\mathrm{i}, \mathrm{t}}-\Delta \ln \mathrm{C}_{\mathrm{w}, \mathrm{t}}=\alpha_{i}+\left(1-\beta_{i}\right)\left(\Delta \ln \mathrm{GDP}_{\mathrm{i}, \mathrm{t}}-\Delta \ln \mathrm{GDP}_{\mathrm{W}, \mathrm{t}}\right)+\varepsilon_{\mathrm{i}, \mathrm{t}},
$$

where $\beta_{i}$ is a country-specific risk sharing measure. This regression is harder to interpret. Even $\beta=1$ does not have much meaning unless the intercept, $\alpha_{i}$, is zero, as otherwise the consumption growth rate of country $i$ is different from the world growth rate during the sample period.

Other regression-based measures, such as those by Artis and Hoffmann (AH) (2006), work with consumption levels instead of consumption growth rates and thus incorporate lowfrequency risk sharing. Yet the work done by $\mathrm{AH}$ is better designed to test perfect risk sharing than to measure how well risks are shared. Consider the following AH regression:

$$
\ln \mathrm{C}_{\mathrm{i}, \mathrm{t}}-\ln \mathrm{C}_{\mathrm{w}, \mathrm{t}}=f_{t}+\left(1-\beta_{t}^{L}\right)\left(\ln \mathrm{GDP}_{\mathrm{i}, \mathrm{t}}-\ln \mathrm{GDP}_{\mathrm{W}, \mathrm{t}}\right)+\varepsilon_{\mathrm{i}, \mathrm{t}},
$$

where $\ln \mathrm{C}_{\mathrm{i}, \mathrm{t}}$ and $\ln \mathrm{C}_{\mathrm{W}, \mathrm{t}}$ are the $\operatorname{logs}$ of per capita consumption in period t for country $i$ and the world, respectively; $\ln \mathrm{GDP}_{\mathrm{i}, \mathrm{t}}$ and $\ln \mathrm{GDP}_{\mathrm{w}, \mathrm{t}}$ are the logs of per capita output in period tor country $i$ and the world; and $\varepsilon_{i, t}$ is an error term.

In this levels regression, perfect risk sharing requires $\beta_{t}^{L}=1$ and $\sigma_{\varepsilon}^{2}=0$. AH find that sequential cross-section estimates of $\beta_{t}^{L}$ are statistically different from unity but become closer 
to unity over time, particularly for EU and EMU countries. While the drift of $\beta_{t}^{L}$ by itself is an indicator that risk might be shared better, it does not make the case tightly because it could be that the variances of $\ln \mathrm{GDP}_{\mathrm{i}, \mathrm{t}}-\ln \mathrm{GDP}_{\mathrm{W}, \mathrm{t}}$ and $\sigma_{\varepsilon}^{2}$ are rising. ${ }^{17}$

In sum, current regression methods provide a good test of perfect risk sharing, but once the null of perfect risk sharing is rejected, they are of little help in assessing how far countries are from the ideal.

\section{Growth Rate Volatility}

Kose, Prasad and Terrones (KPT) (2003b) study the volatility of the consumption growth rate, income growth rate, and output growth rate for each country. They infer the degree of risk sharing from these measures. However, such inferences are problematic since both trade and financial integration have ambiguous theoretical effects on these volatilities, as they note. For example, suppose there are two countries, one with a constant endowment and the other with a volatile endowment. Optimal risk sharing reduces consumption volatility in one country but increases it in the other, with output volatilities unchanged. Now measure risk sharing as the ratio of the volatility of the total consumption growth rate to that of the income growth rate as in KPT. ${ }^{18}$ Complete Arrow-Debreu securities allow national income and its growth to be insured over time and state as well as consumption. ${ }^{19}$ Thus using the ratio of these volatilities is not correct from a theoretical point of view.

\section{A New Measure of Risk Sharing $(\sigma)$}

We wish to measure how closely countries come to the benchmark of perfect risk sharing when the null of perfect risk sharing is rejected. We want a simple measure, but one that is closely tied to the theory and thus yields welfare implications. We therefore compute over different time intervals the squared deviations of the log of the ratio of individual-country percapita consumption to the share-weighted average of rest-of-the-world per-capita consumption. We show in section B. that our measure is linked to social welfare. .

\section{A. $\sigma$ Measure}

Over some time interval, the variance of country $i$ 's log share of world consumption is

$$
\hat{\sigma}_{i, \tau}^{2}=\frac{1}{T} \sum_{t=0}^{T}\left(X_{i, t}-\bar{X}_{i}\right)^{2}
$$

\footnotetext{
${ }^{17}$ This is a fine point. In fact, $\mathrm{AH}$ interpret their results as showing that risk sharing has been improving for industrial countries at low frequencies, which is consistent with our results.

${ }^{18}$ Kose et. al. use GNP refined by the terms of trade as an income measure.

${ }^{19}$ Indeed, Asdrubali, Sorensen and Yosha (1996) find that income risk sharing contributes most in terms of interstate consumption risk sharing in the US.
} 
where $X_{i, t}=\ln \left(C_{i, t}\right)-\ln \left(C_{W, t}\right), \bar{X}_{i}$ is the sample mean of $X_{i, t}$ for the corresponding period, and $\tau$ is the end of the sample period. In the benchmark case of perfect risk sharing, $X_{i, t}=\bar{X}_{i}$ for all $t$, where $\bar{X}_{i}$ is a constant related to initial wealth or a social planner's weights as in equation (3). The variance measure in (10) is our measure of risk sharing. As the measure approaches zero, the benchmark for perfect risk sharing, country $i$ increasingly shares risk internationally. Unlike correlation measures or time-series regression-based measures, when our measure is zero, it implies that a country has achieved perfect risk sharing with the rest of the world.

Recall the example given in equation (4). Even if $g_{1}=g_{2}$ in equation (4), our measure will not conclude that country $i$ is sharing risk perfectly on average unless $\lambda$ is unity, because over a sample period of length $T$,

$$
\hat{\sigma}_{i, \tau}^{2}=\frac{1}{T} \sum_{t=0}^{T}\left(X_{i, t}-\bar{X}_{i}\right)^{2}=(1-\lambda)^{2} \frac{1}{T} \sum_{t=0}^{T} \varepsilon_{t}^{2} \underset{T \rightarrow \infty}{\longrightarrow}(1-\lambda)^{2} \sigma_{\varepsilon}^{2}
$$

where $\sigma_{\varepsilon}^{2}$ is the variance of $\varepsilon_{t}$. Note that our measure does not aim to gauge the level of risk sharing among particular groups of countries as in Kalemli-Ozcan et. al. (2003). Our measure focuses instead on the degree of risk sharing over some time period for a country pair or for each country relative to the world.

Like other measures, our measure does not distinguish whether a country achieves higher risk sharing intentionally or by chance. But it does have some clear advantages. It is tied to welfare, as shown below. It also provides some insight about the source of improved risk sharing -- whether it comes from business cycle synchronization or from growth rate convergence.

\section{B. Social Welfare and Our $\sigma^{2}$ Measure}

This section illustrates how our measure of risk sharing is linked to social welfare in a simple two-agent economy.

Let social welfare be

$$
S_{t}=\lambda u\left(C_{1, t}\right)+(1-\lambda) u\left(C_{2, t}\right)
$$

subject to $C_{1, t}+C_{2, t}=C_{W, t}$. The utility function is increasing and concave and depends only on contemporaneous consumption. Then, optimal allocations solve:

$$
\lambda u^{\prime}\left(C_{1, t}\right)-(1-\lambda) u^{\prime}\left(C_{W, t}-C_{1, t}\right)=0
$$

Let the solution be $C_{1, t}^{*}=\kappa_{1} C_{W, t}$ and $C_{2, t}^{*}=\left(1-\kappa_{1}\right) C_{W, t}$. Define social welfare with the optimal allocation: $S_{t}^{*} \equiv \lambda u\left(C_{1, t}^{*}\right)+(1-\lambda) u\left(C_{2, t}^{*}\right)$. Now, any allocation can be written as

$$
\begin{aligned}
& C_{1, t}=\left(\kappa_{1}+v_{t}\right) C_{W, t}, \\
& C_{2, t}=\left(1-\kappa_{1}-v_{t}\right) C_{W, t}
\end{aligned}
$$


We evaluate the social welfare of the actual allocation by taking the second-order approximation of the social welfare function.

$$
\begin{aligned}
S_{t} & =\lambda u\left(C_{1, t}\right)+(1-\lambda) u\left(C_{2, t}\right) \\
& \approx \lambda u\left(C_{1, t}^{*}\right)+(1-\lambda) u\left(C_{2, t}^{*}\right)+\lambda u^{\prime}\left(C_{1, t}^{*}\right) v_{t} C_{W, t}-(1-\lambda) u^{\prime}\left(C_{2, t}^{*}\right) v_{t} C_{W, t} \\
& +\lambda \frac{1}{2} u^{\prime \prime}\left(C_{1, t}^{*}\right)\left(v_{t} C_{W, t}\right)^{2}+(1-\lambda) \frac{1}{2} u^{\prime \prime}\left(C_{2, t}^{*}\right)\left(v_{t} C_{W, t}\right)^{2}
\end{aligned}
$$

We then compare this actual allocation to the optimal allocation.

$$
\begin{aligned}
S_{t}-S_{t}^{*} \approx & \underbrace{\left[\lambda u^{\prime}\left(C_{1, t}^{*}\right)-(1-\lambda) u^{\prime}\left(C_{2, t}^{*}\right)\right]}_{=0} v_{t} C_{W, t} \\
& +\underbrace{\left[\lambda \frac{1}{2} u^{\prime \prime}\left(C_{1, t}^{*}\right)+(1-\lambda) \frac{1}{2} u^{\prime \prime}\left(C_{2, t}^{*}\right)\right]\left(C_{W, t}\right)^{2} v_{t}^{2}}_{<0}
\end{aligned}
$$

The first bracketed term in (13) is zero because of the envelope theorem or equation (12). The second bracketed term is negative because of the concavity of the utility function. Thus (13)

implies that maximizing social welfare is equivalent to minimizing $v_{t}{ }^{2}$, which is our measure of risk sharing since

$$
v_{t} \approx \ln \left(C_{i, t}\right)-\ln \left(C_{W, t}\right)-\kappa
$$

\section{Frequency Decomposition}

In our model and in the real world, countries experience both high frequency risks such as those at the business-cycle frequency - and low-frequency risks realized as differences in average consumption growth rates for sample periods. So far, we follow theory literally by combining these risks in our measure. It is interesting, none-the-less, to investigate the source of our measured risk-sharing improvement. Is it high-frequency risks or is it consumption-growth rate convergence?

We can provide insight into our risk sharing measure by decomposing it into high- and low-frequency components. The high-frequency component is the deviation from sample trend. The low-frequency component is the difference between trends, or the difference in consumption growth rates between country $i$ and the world. We now provide the analytics for decomposing our risk measure and then study the decomposition in our sample.

Let $g$ be the average growth rate of $X_{i, t}\left(=\ln C_{i, t}-\ln C_{W, t}\right)$ for $T$ periods. Formally,

$$
g_{i}=\frac{1}{T}\left(X_{i, t}-X_{i, t-T}\right)
$$

Then our risk-sharing measure in (10) can be re-written as 


$$
\begin{aligned}
\frac{1}{T} \sum_{n=0}^{T}\left(X_{i, t-n}-\bar{X}_{i}\right)^{2}= & \frac{1}{T} \sum_{n=0}^{T}\left\{X_{i, t-n}-\left(X_{t}-g_{i} n\right)+\left(X_{t}-g_{i} n-\bar{X}_{i}\right)\right\}^{2} \\
= & \frac{1}{T} \sum_{n=0}^{T}\left[X_{i, t-n}-\left(X_{t}-g_{i} n\right)\right]^{2} \\
& +\frac{1}{T} \sum_{n=0}^{T}\left(X_{i, t}-g_{i} n-\bar{X}_{i}\right)^{2} \\
& +\frac{1}{T} \sum_{n=0}^{T} 2\left[X_{i, t-n}-\left(X_{t}-g_{i} n\right)\right]\left(X_{i, t}-g_{i} n-\bar{X}_{i}\right)
\end{aligned}
$$

The first term, $\frac{1}{T} \sum_{n=0}^{T}\left[X_{i, t-n}-\left(X_{i, t}-g_{i} n\right)\right]^{2}$, measures the high-frequency component. The second term, $\frac{1}{T} \sum_{n=0}^{T}\left(X_{i, t}-g_{i} n-\bar{X}_{i}\right)^{2}$, captures the difference in average growth rates between country $i$ and the world, which is often excluded from existing measures. We call this the lowfrequency component, or the growth-difference component. Finally, the third term measures the interaction.

The shaded area in Figure 1 illustrates the key components of our measure. The area between the trend line and $X_{i, t-s}$ captures the high-frequency component, or the term $\frac{1}{T} \sum_{n=0}^{T}\left[X_{i, t-n}-\left(X_{i, t}-g_{i} n\right)\right]^{2}$. The two triangular areas between the trend line and the average, $\bar{X}$, capture the difference in average growth rates, or the term $\frac{1}{T} \sum_{n=0}^{T}\left(X_{i, t}-g_{i} n-\bar{X}_{i}\right)^{2}$, that is ignored by popular measures of risk sharing..$^{20}$

\section{TAking The NeW Measure to Data}

We construct our risk sharing measure using data from the Penn World Tables, Version 6.2 (Heston, Summers and Aten 2006). We create our world consumption index by accumulating weighted-average growth rates of per-capita consumption in countries regarded as the world. The definition of 'world' in our study is simply the rest of the countries in our sample. ${ }^{21}$ Different definitions of 'world' do not significantly change our results because aggregate world consumption is determined mainly by major industrial countries. The importance of the industrial countries implies also that if the quality of the data in these countries is good, then even if there are a few countries with data quality issues, the main

\footnotetext{
${ }^{20}$ For example, the correlation and $\beta$ measures are usually derived from growth rate data or detrended data and are therefore high-frequency measures only.

${ }^{21}$ Kose et al (2007) define 'world' as the set of industrial countries. Relative to a particular industrial country, the 'world' is the rest of the industrial countries.
} 
conclusion regarding each group of countries will not change much as our risk sharing measure uses only world and own consumption levels. Of course, risk sharing measures regarding individual countries depend crucially on the individual countries' data quality. We use data on private consumption, but the results are very similar when we use total (private plus public) consumption. ${ }^{22}$

\section{A. Results and Comparison with Existing Measures}

Figures 2 and 3 depict the within-group averages of our measure of risk sharing for three groups of countries: Industrial Countries ("Industrial"), More Financially Integrated Emerging Market Countries (MFIE), and Less Financially Integrated Emerging Countries (LFIE), rolling over time. ${ }^{23}$ The measures plotted in the figures, $\hat{\sigma}_{t, i, 15}$ and $\hat{\sigma}_{t, i, 20}$, are the simple averages of the standard deviations of relative consumption for each country group computed in rolling windows of length 15 and 20 years, respectively. The windows end at date $t$ and pertain to country group $i . \quad \hat{\sigma}_{2003, M F I E, 15}$, for example, is the simple cross-country-average standard deviation of $\log \left(C_{i, s} / C_{w, s}\right)$ for the MFIE country group computed in a 15-year window ending in 2003.

Figures 4, 5 and 6 attach 90\% bootstrapped confidence intervals to the estimates in Figure 2. We find that emerging countries, MFIE and LFIE, did, indeed, improve (point estimate) risk-sharing during the recent globalization era, since about 1995, after having experienced a worsening in the early sample period, although the confidence interval is too wide to be conclusive and statistical significance of the improvement for LIFE and MIFE is debatable. Industrial countries, on the other hand, improved risk sharing significantly in the 1970s and early 1980s but have not shown much change thereafter. For the entire sample period, regardless of the length of the window, we find a robust and intuitive ranking of country groups' risk sharing - industrial countries share risks best, MIFE second and LFIE last.

Figures 7 and 8 depict scatterplots of $\hat{\sigma}_{2003, i, 15}$ and $\hat{\sigma}_{1964, i, 15}$, on a country-by-country basis, against the logarithm of per-capita country consumption for the last year of the sample period, 2003 or $1964 .{ }^{24}$ In both figures, there is always the tendency for richer countries to share risks better than poorer ones.

Moreover, the risk-sharing order of countries rarely changes. In

\footnotetext{
22 We use $r g d p l$ (I\$ in 2000 Constant Prices) times $k c$ (Consumption Share of $r g d p l$ ) as per capita private consumption and $r g d p l$ times $k c+k g$ as per capita total consumption. For a detailed description, see Heston, Summers and Aten (2006) For our derivation of world per capita consumption, see the Appendix.

${ }^{23}$ Our country groupings are from Kose et al (2003a) and are listed in the Appendix.

${ }^{24}$ We should be cautious about interpreting the earlier sample because some countries, such as Japan, are categorized as "Industrial" but were actually middle income.
} 
Figure Figure 9, we pull out of our aggregated groups the results for India, Japan and the U.S. as examples. The figure shows that the U.S., for most of the period, shares risks better than India and Japan. Japan did not share risks well early in our sample since its growth miracle increased per capita consumption faster than the world average.

Figures 10 and 11 depict group averages and country examples, respectively, of correlations of annual growth rates of per capita consumption with the annual growth rate of world per capita consumption. In Figures 10 and 11, higher correlations indicate better risk sharing. Figure 10, which shows no long-term increase in the correlations, is often regarded as evidence that emerging countries have not benefited from globalization. Figure 11 shows the correlation measure is an unreliable indicator of risk sharing since its ranking is sensitive to the sample period. The reason is likely due to the fact that the correlation measure ignores the average growth rate of a country for the sample period and hence does not capture a key component of risk sharing.

Figures 12 and 13 depict group averages and country examples of the rolling time series " $\beta$ measures" used by Kose et. al (2007). The value for the Y axis is $\beta_{i}$, defined in equation (8), and higher values may indicate better risk sharing. Counter intuitively, the $\beta$ measures graphed in Figures 12 and 13 indicate that less financially integrated countries share risks better than industrial countries. When we use total consumption in the place of private consumption and a rolling window of 10 years instead of 15 , then the $\beta_{i}$ 's of industrial countries are higher. The $\beta_{i}$ measure is sensitive to the precise choice of variables, rolling windows length, and definition of 'world'. Consequently, $\beta_{i}$ is not a robust measure of risk sharing.

\section{B. Results of High-Low Frequency Decomposition}

Figures 14 and 15 depict the decomposition of our measure by showing the crosscountry means of the first and the second terms of equation (7) over time. Lower values indicate better risk sharing. In Figure14, we see that the high-frequency component is without trend for all country groups and it is quite noisy for MFIE and LFIE. This is probably the reason why the existing measures, whose focus is high frequency, cannot detect improved risk sharing.

However, from Figure 15 we see that the low-frequency component is without trend over the full sample period for MFIE and LFIE, but shows an improvement more recently. For the Industrial countries, we see dramatic improvement early in the sample period. Indeed, the early improvement is so strong that there is little room for additional low-frequency improvement later on.

Note that while we find improved risk sharing is mostly due to convergence in consumption growth rates, our finding should be distinguished from a simple growth convergence story. ${ }^{25}$ Growth convergence suggests poor countries eventually catch up to the output levels of rich countries. Even if two countries do not share risks, they will eventually

\footnotetext{
${ }^{25}$ Devereux and Saito (1997) derive conditions for convergence in growth rates in a model with incomplete asset markets. In general, convergence is not guaranteed.
} 
achieve convergence in consumption levels. Our measure would pick up the lack of risk sharing since the poor country's consumption share in world consumption would be increasing during the growth convergence process. Indeed, Japan in the earlier sample period, and China in the later sample period, exhibit poor risk sharing since their consumptions grew very fast.

It should be also noted that the simple convergence story implies that growth rates will become zero. Typically, economists assume that total factor productivity (TFP) grows exogenously, but that does not imply convergence in consumption growth rates in autarky unless long-run exogenous growth rates of TFP happen to be the same among countries by chance or assumption. Convergence in consumption growth rates happens when countries share risks. Note that we do not exclude the possibility of risk sharing through technological transfer. While consumption risk sharing is accomplished through income transfers only in simple endowment economies, broader risk sharing can be achieved by technological transfers as well as income transfers in production economies.

\section{Conclusion}

We propose a simple measure of international risk sharing when risk sharing is not perfect. Our measure gauges the degree of risk sharing rather than tests for perfect risk sharing. Unlike previous measures derived from hypothesis testing, our measure is a welfare-based one that allows for economic interpretation. When our measure is zero, it implies perfect risk sharing. In addition, our measure shows to what extent greater risk sharing is due to increased business-cycle synchronization and convergence in growth rates.

We apply our measure of international risk sharing to the data. We find that countries on average are sharing risk better during the era of financial globalization than previously. While this finding should not be surprising, it is not what existing measures uncover. The reason is that existing measures ignore consumption growth-rate differences and focus on whether per capita consumption across countries is synchronized at the business-cycle frequency. Our measure considers both low-frequency and high-frequency elements.

The risk sharing we uncover is not short-term, brought about through insurance contracts or trading country- risk-specific securities. It is a long-term phenomenon, driven perhaps by output-growth-rate convergence related to trade in ideas and technologies and to diffusion of institutions, which Kose, Prasad, Rogoff and Wei (2006) call the collateral benefits of globalization. Our measure may not be an ideal test for perfect risk sharing, but our measure is consistent with the existing view that perfect risk sharing remains a distant goal. Moreover, our new measure shows that the degree of risk sharing has improved over time because industrial countries' consumption growth rates have converged dramatically since the 1960s and consumption growth rates for emerging markets started converging in the 1990s. 
Figure 1. Lack of Perfect Risk Sharing Due to Difference in Trend Growth and Deviation from Trend

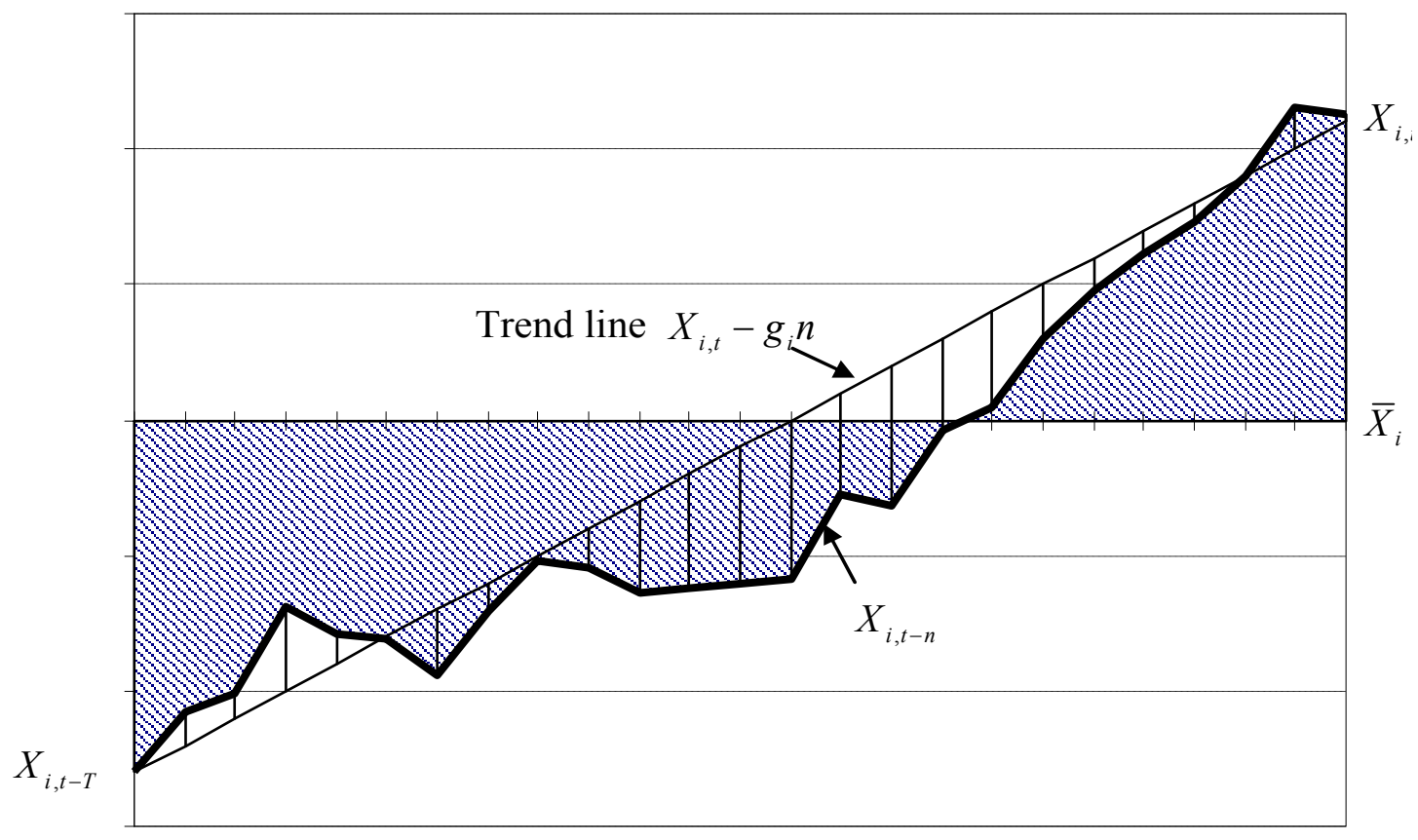


Figure 2, Rolling Volatility (mean) $\mathrm{rw}=15$

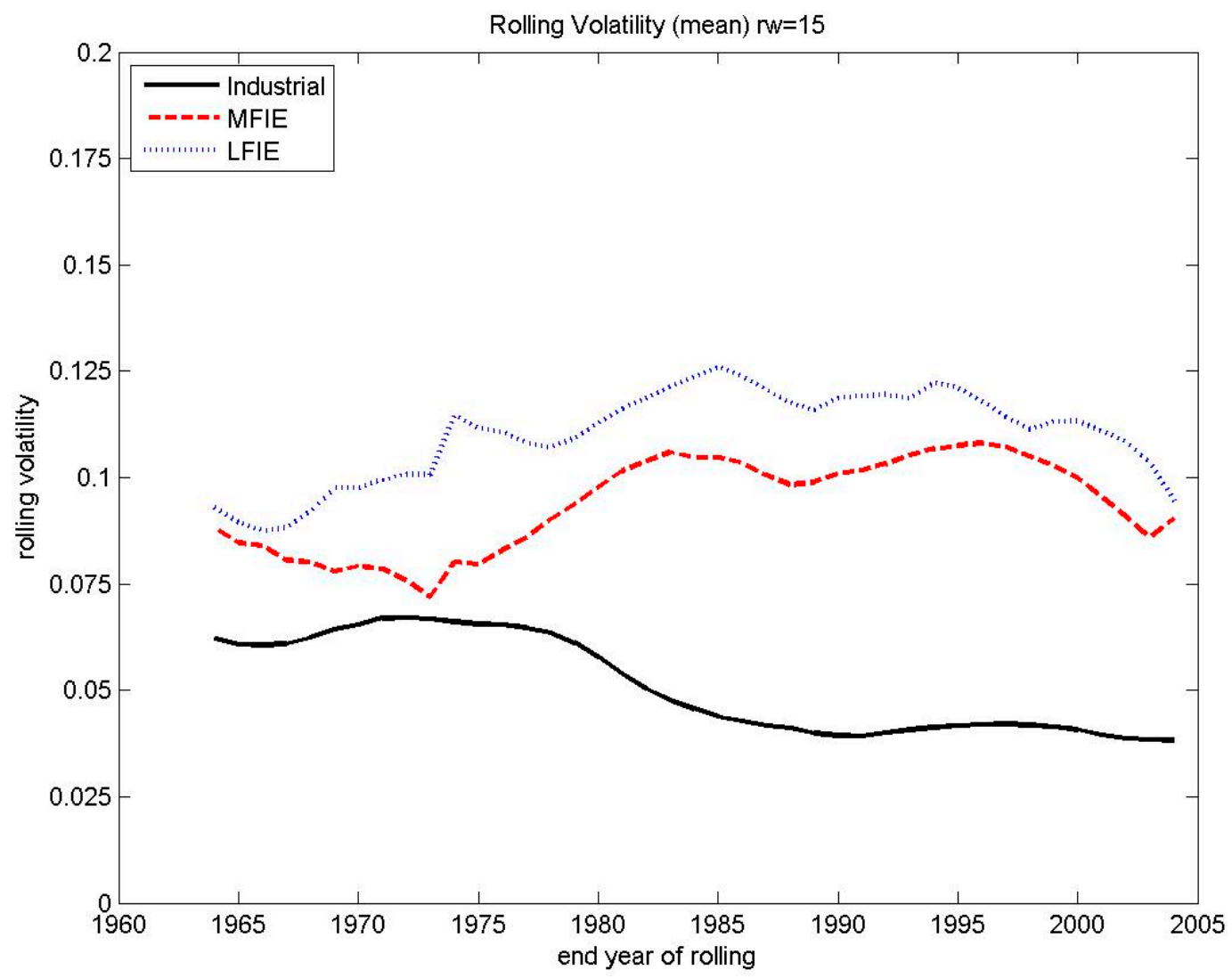


Figure 3. Rolling Volatility (mean) $\mathrm{rw}=20$

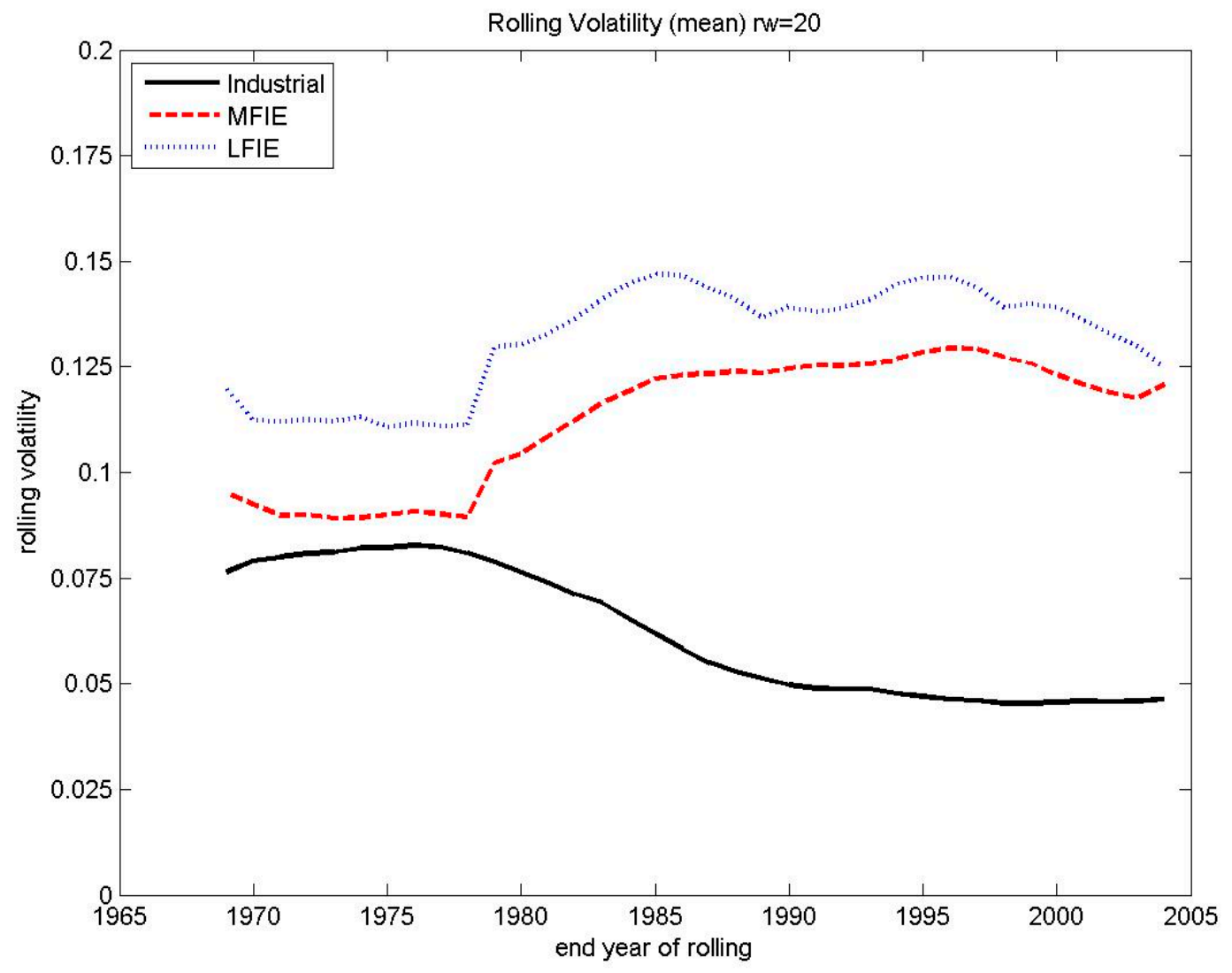


Figure 4. Rolling Volatility (mean) $\mathrm{rw}=15$

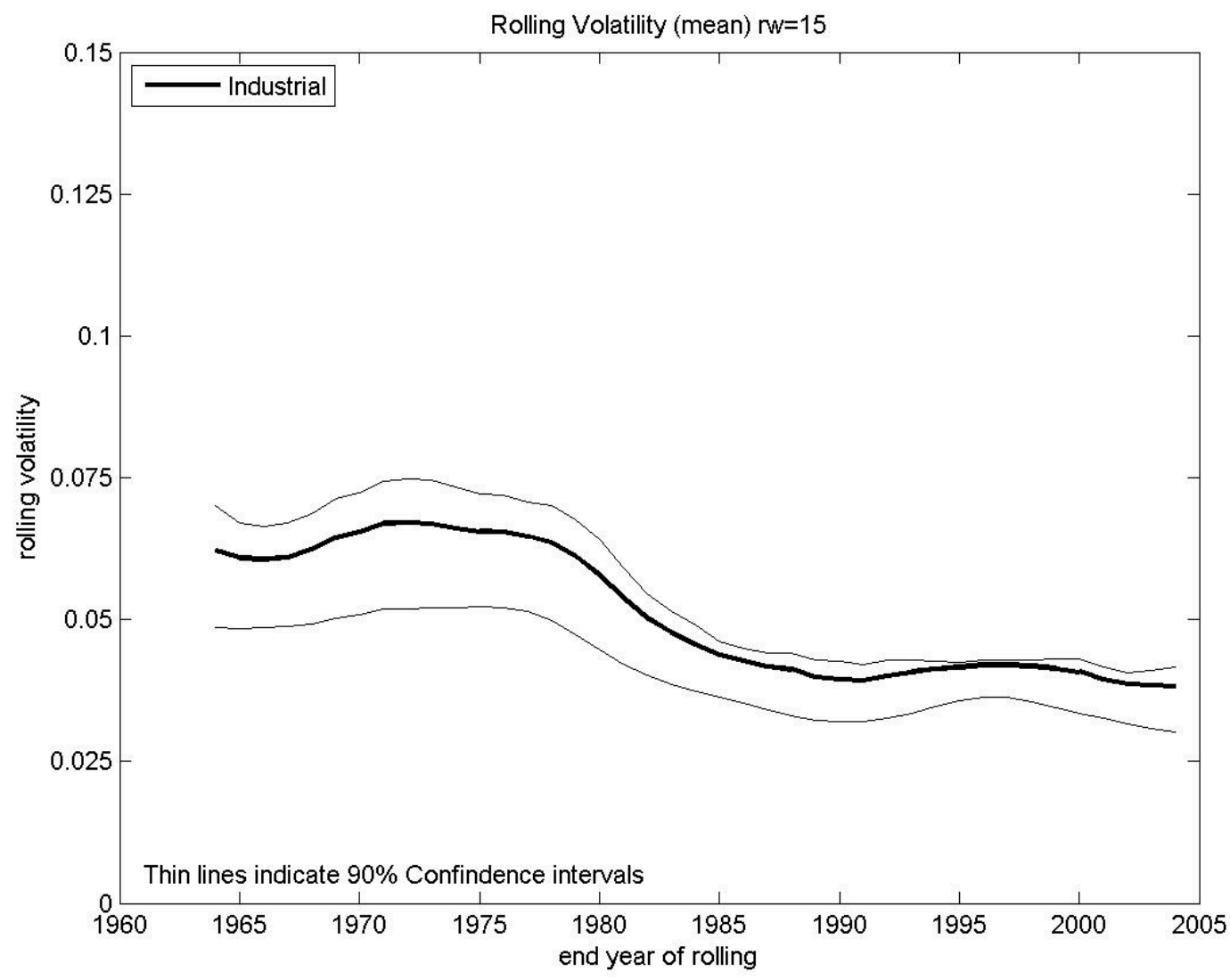


Figure 5. Rolling Volatility (mean) $\mathrm{rw}=15$

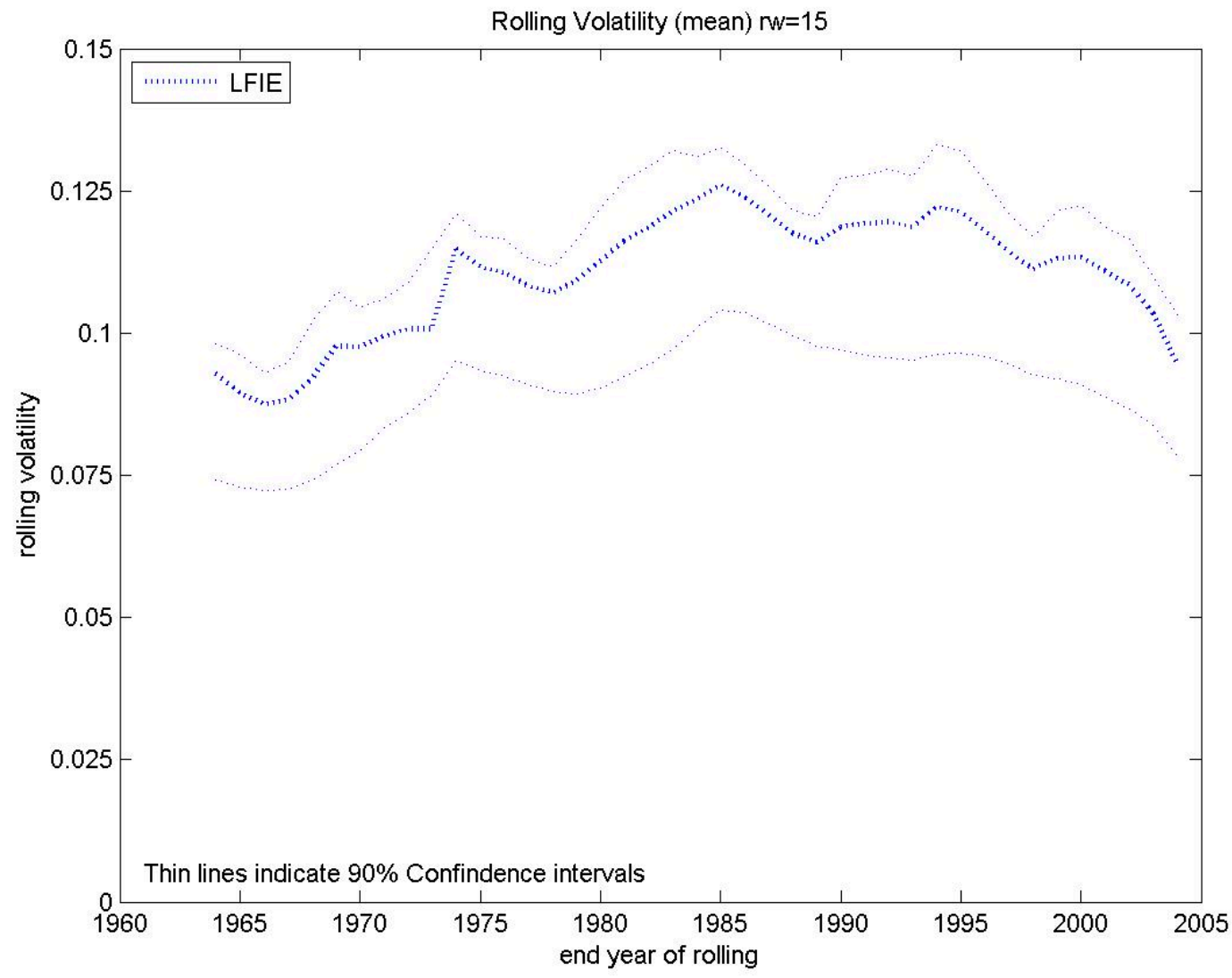


Figure 6. Rolling Volatility (mean) $\mathrm{rw}=15$

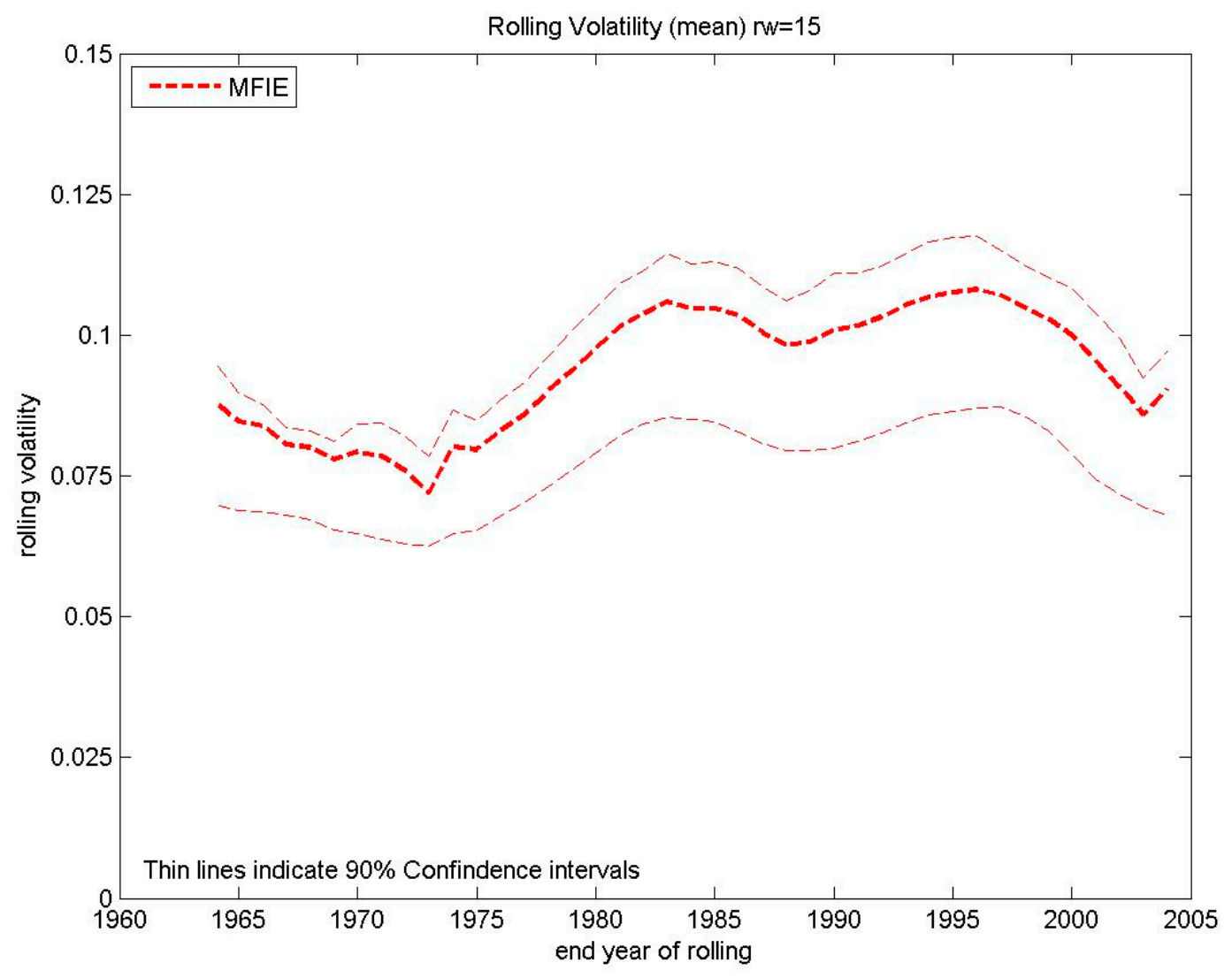


Figure 7. Relation Between the degree of Risk Sharing and National Income in 2003

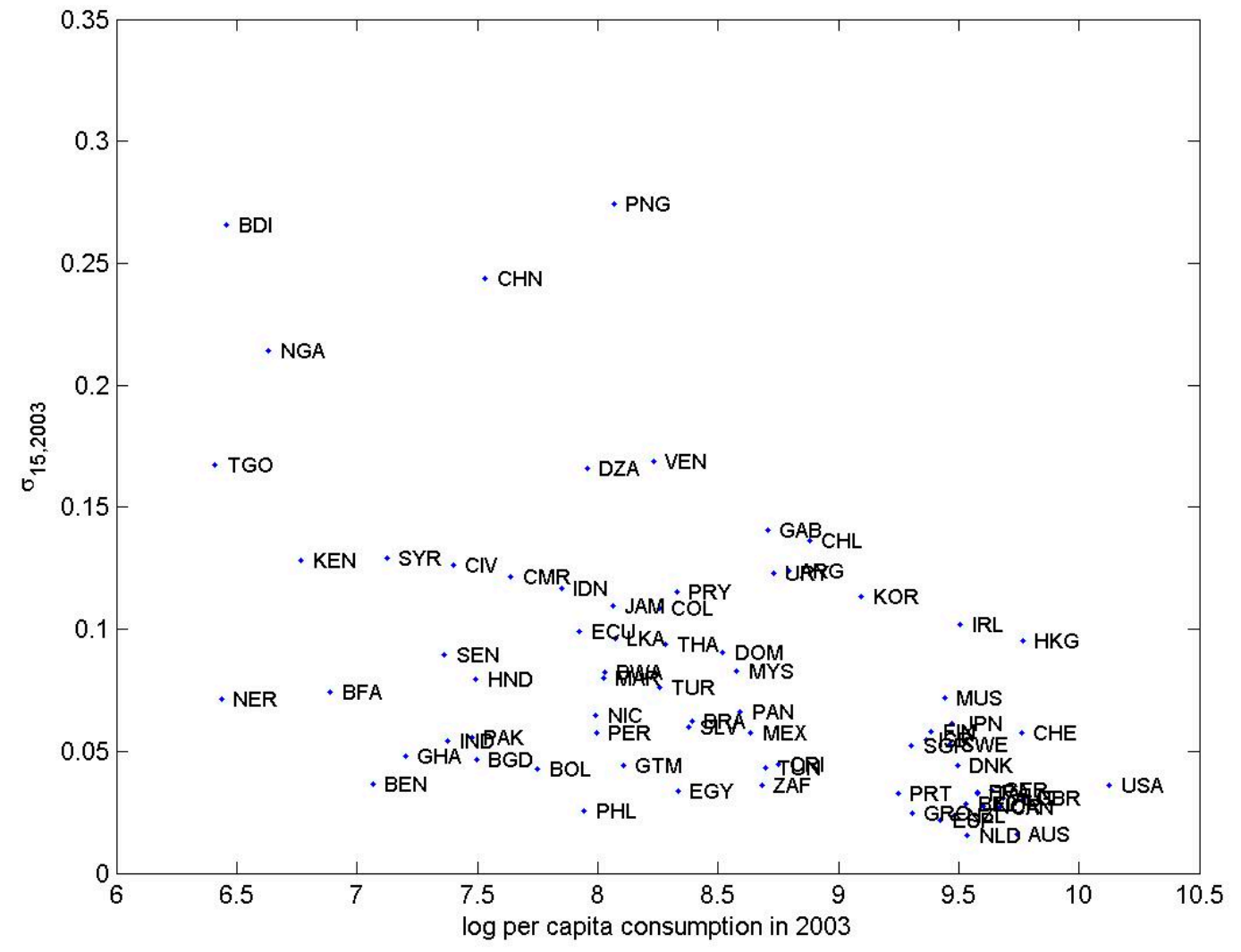


Figure 8. Relation Between the Degree of Risk Sharing and National Income in 1964

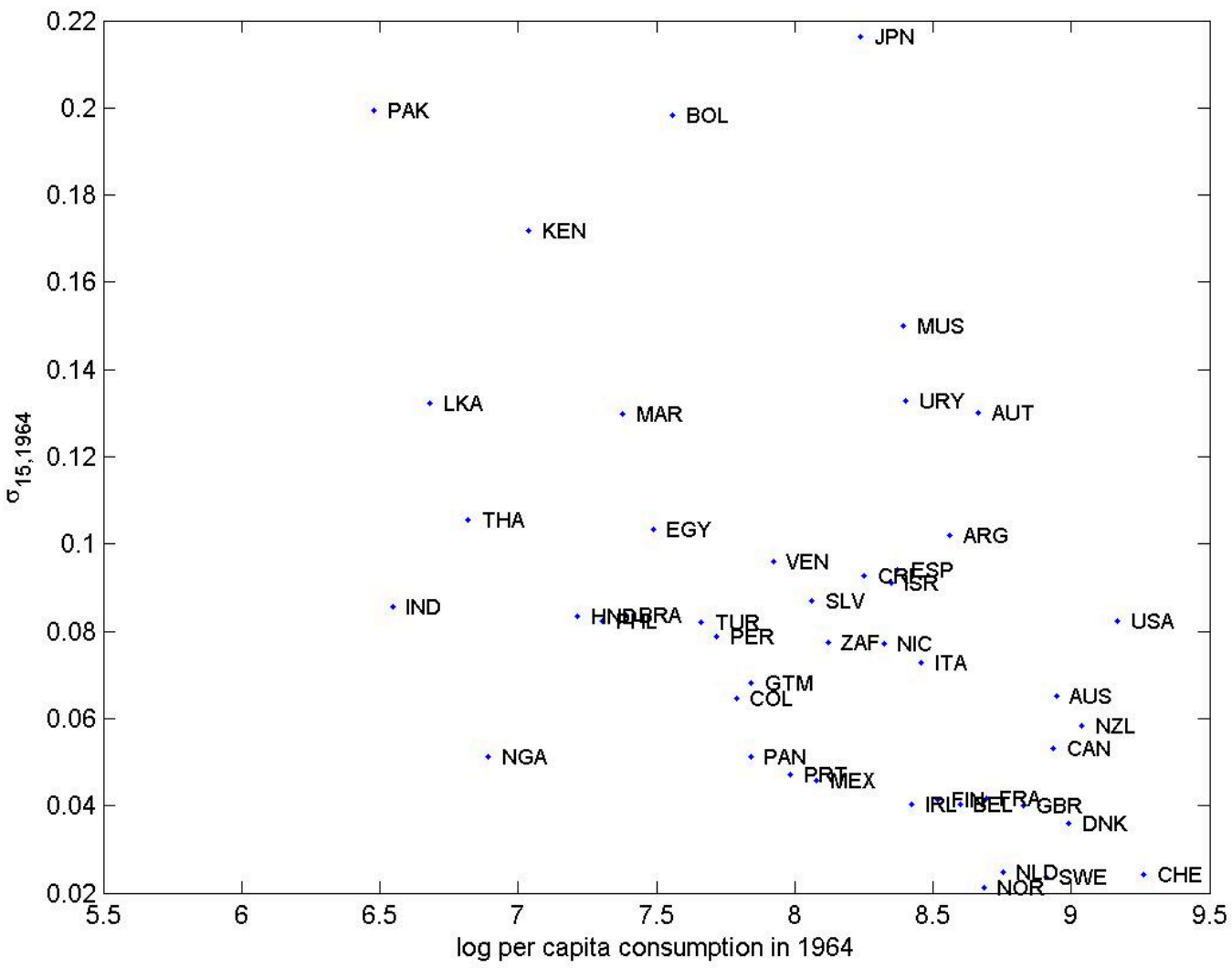


Figure 9. $\sigma_{15}$ Measure Over Time

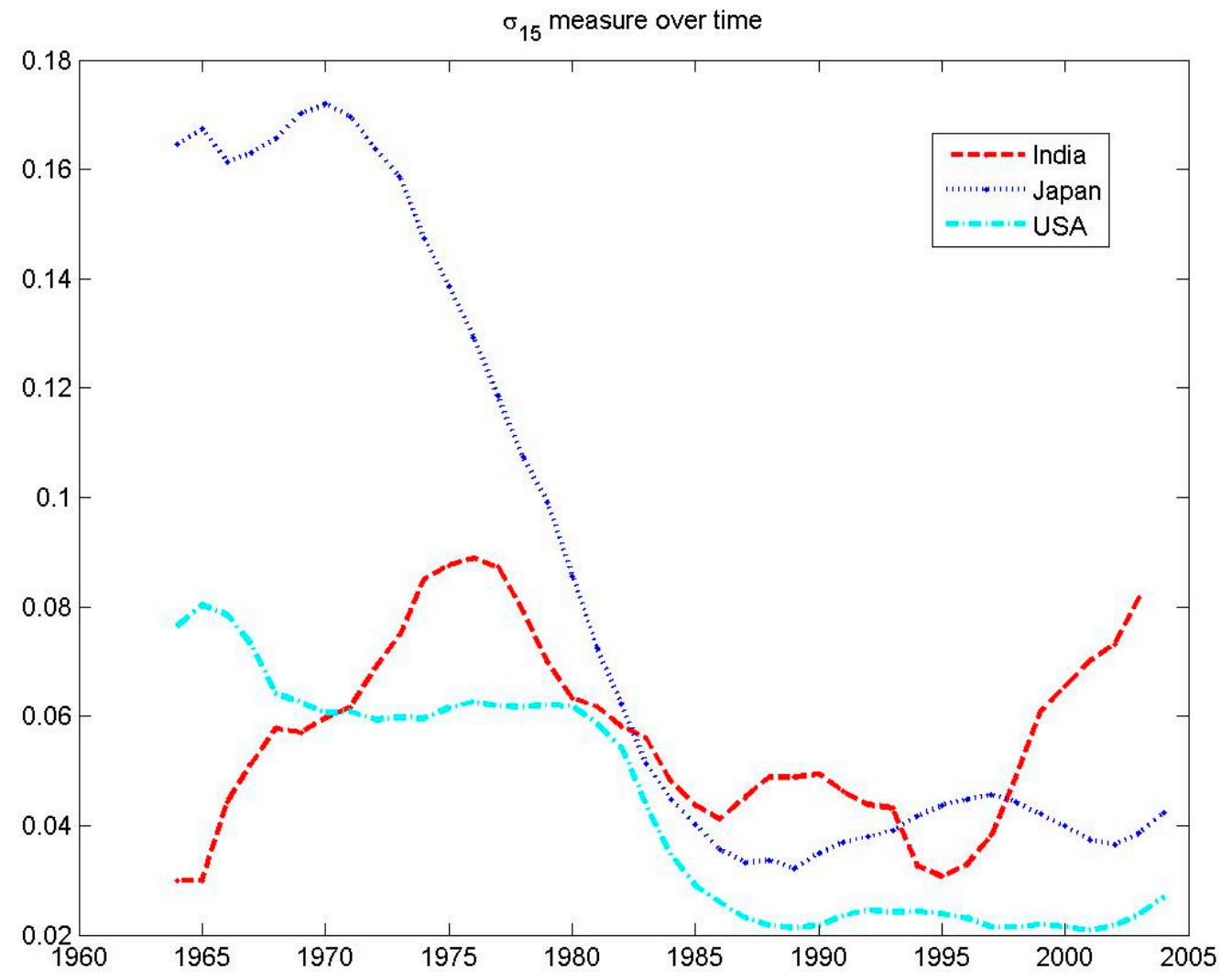


Figure 10. Correlation (mean) $\mathrm{rw}=15$

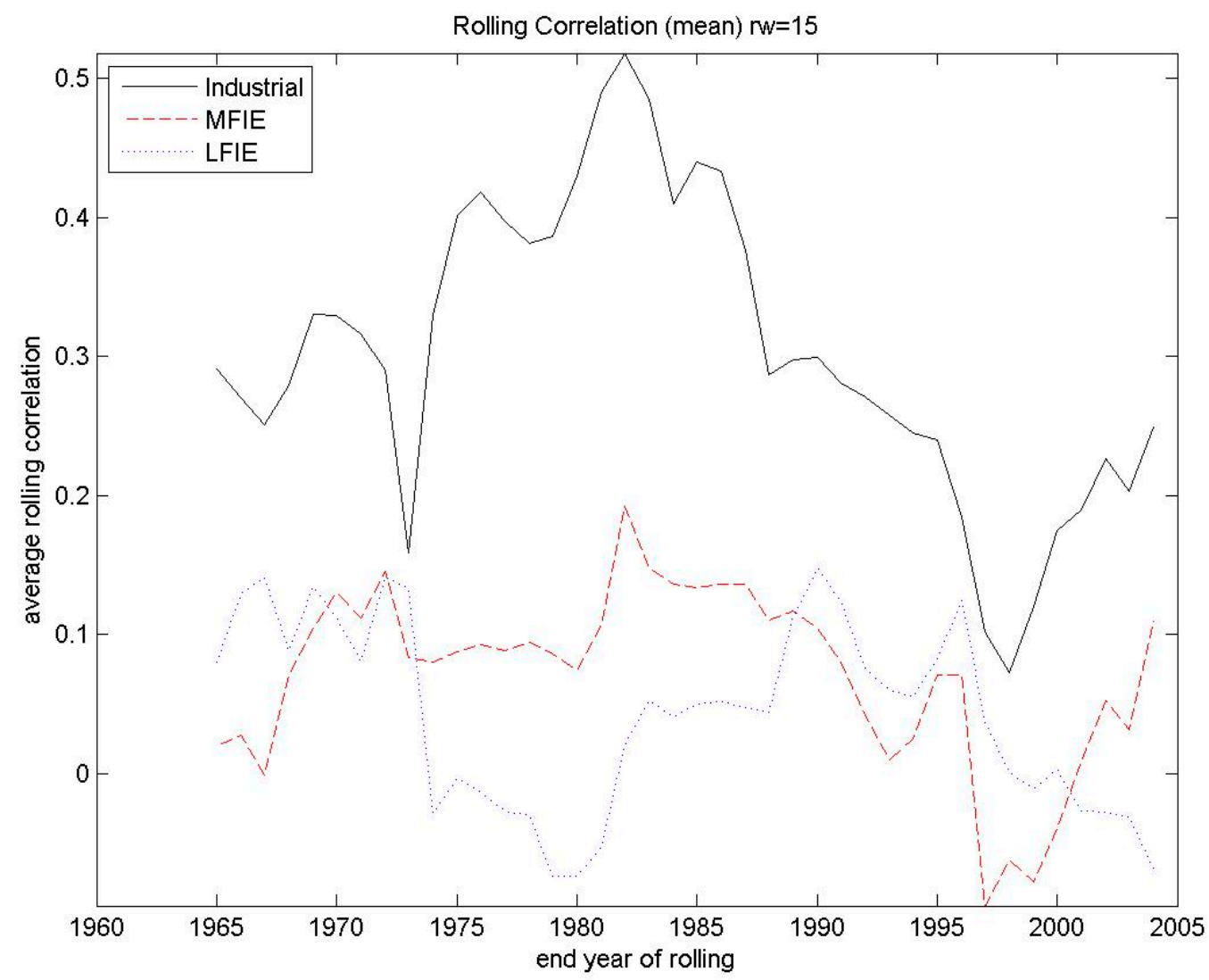


Figure 11. Correlation Measure Over Time15-year rolling

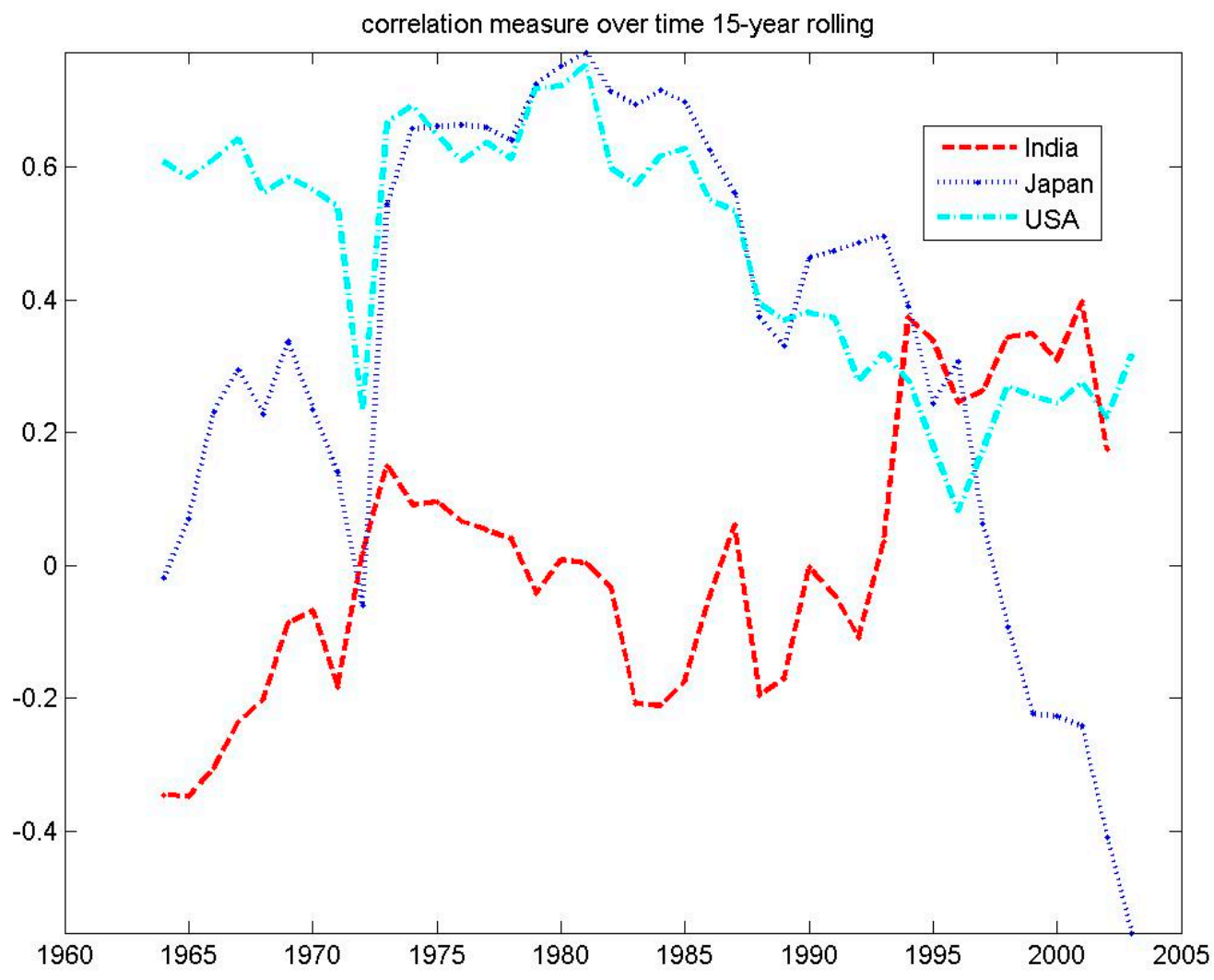


Figure 12. Rolling $\beta$ (median) $\mathrm{rw}=15$

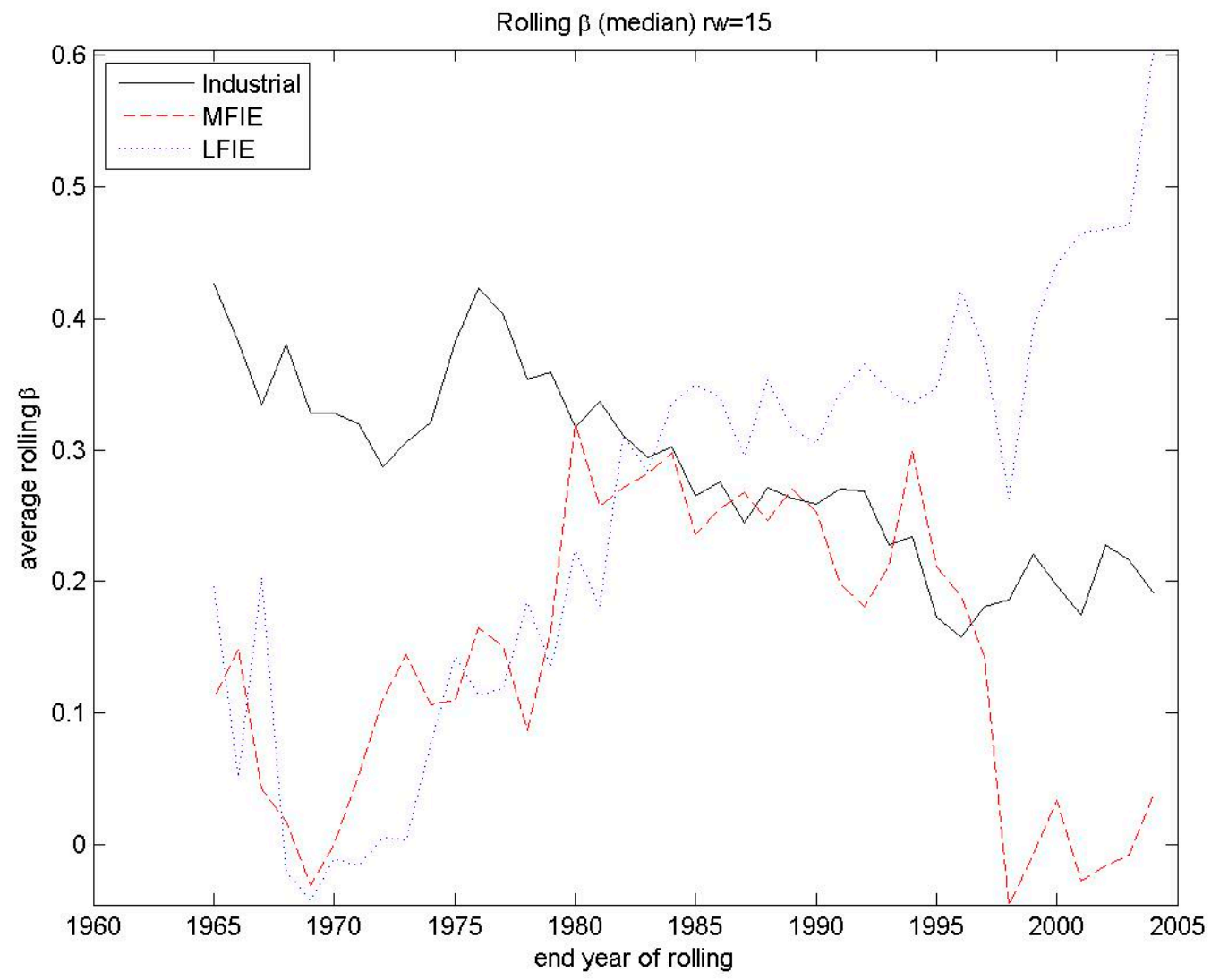


Figure 13. $\beta$ Measure Over Time 15-year Rolling

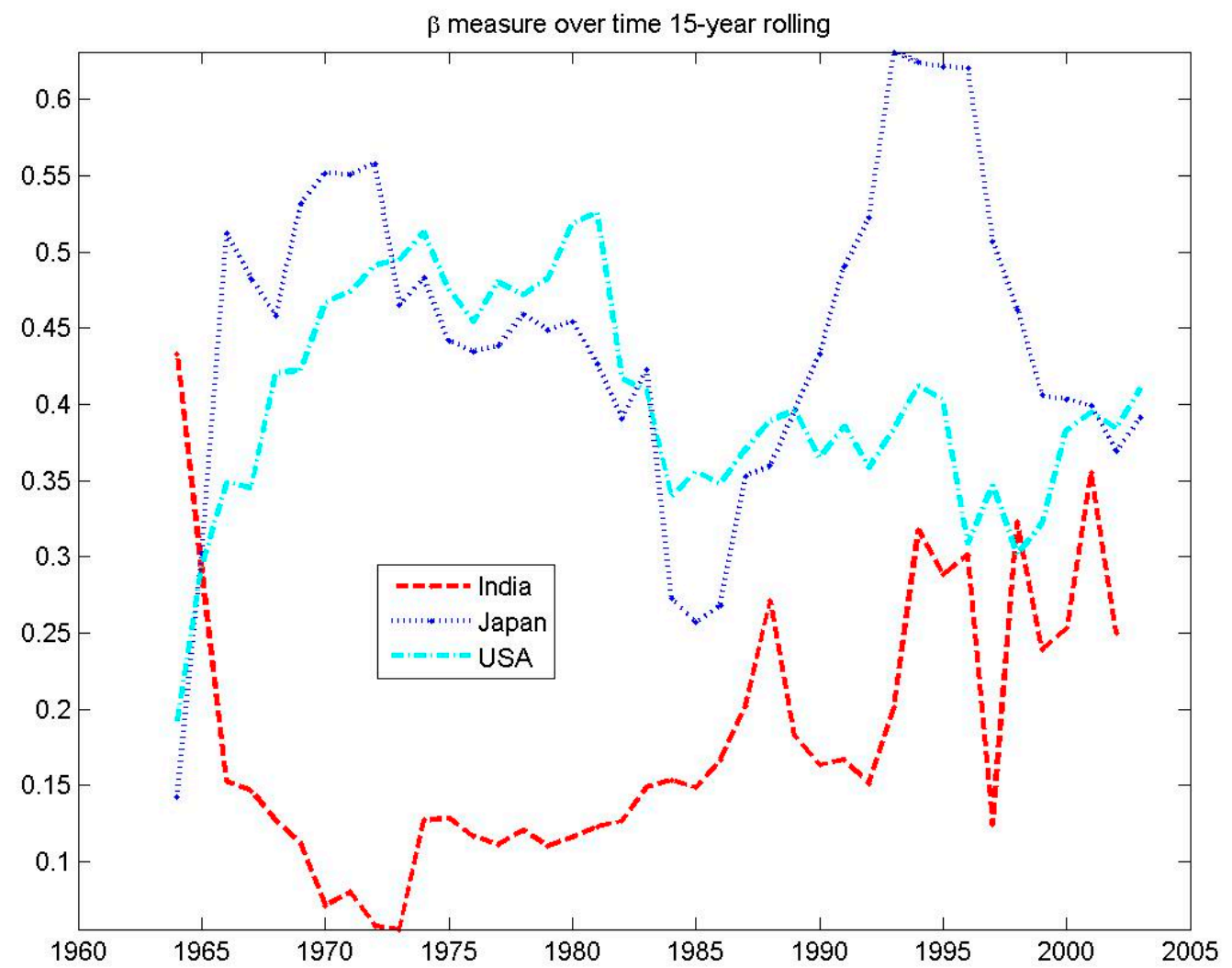


Figure 14. Rolling $\mathrm{RVC}_{\mathbf{h}}$ (mean) $\mathrm{rw}=15$

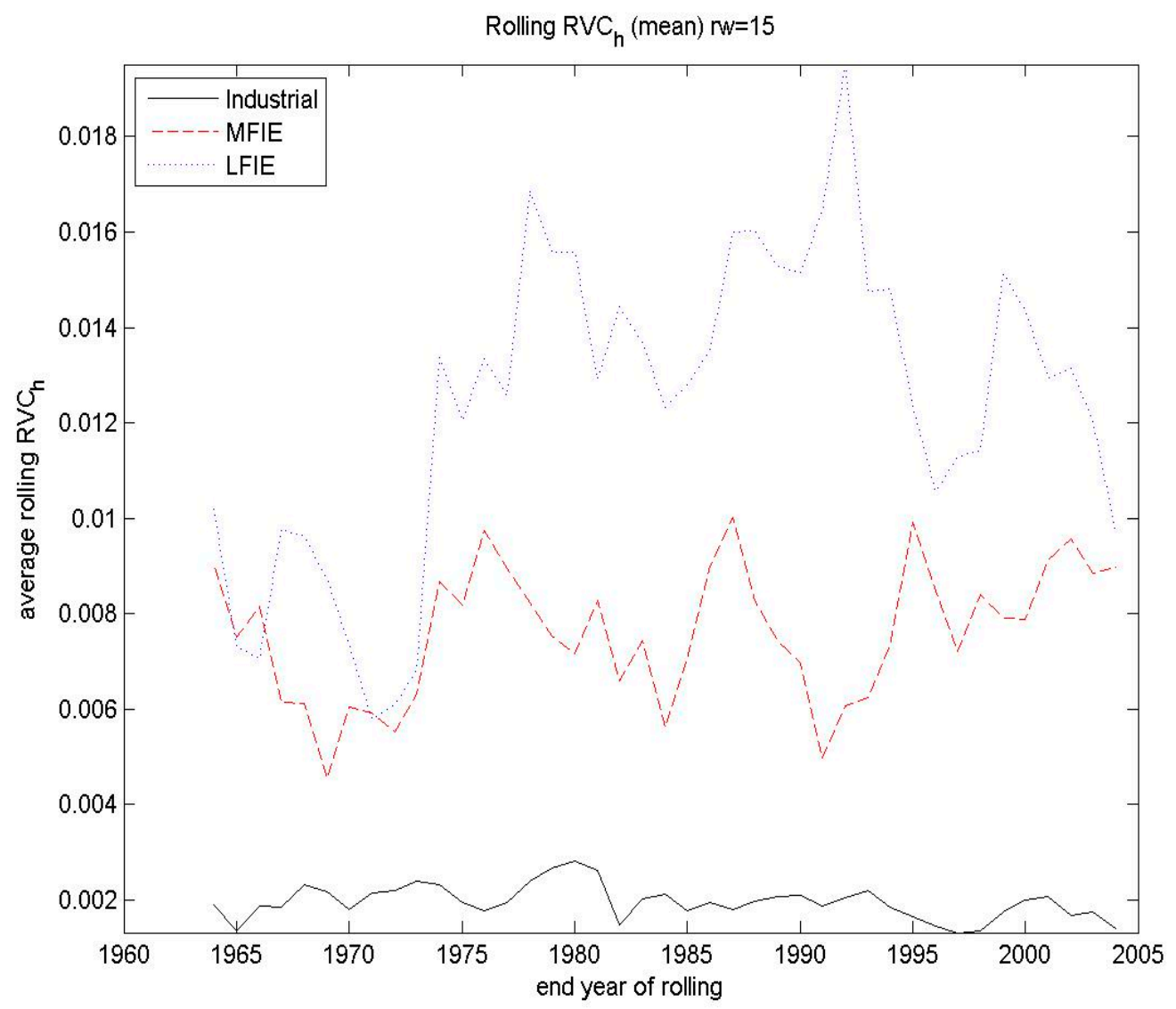


Figure 15. Rolling $\mathrm{RVC}_{\mathbf{G}}$ (mean) $\mathrm{rw}=15$

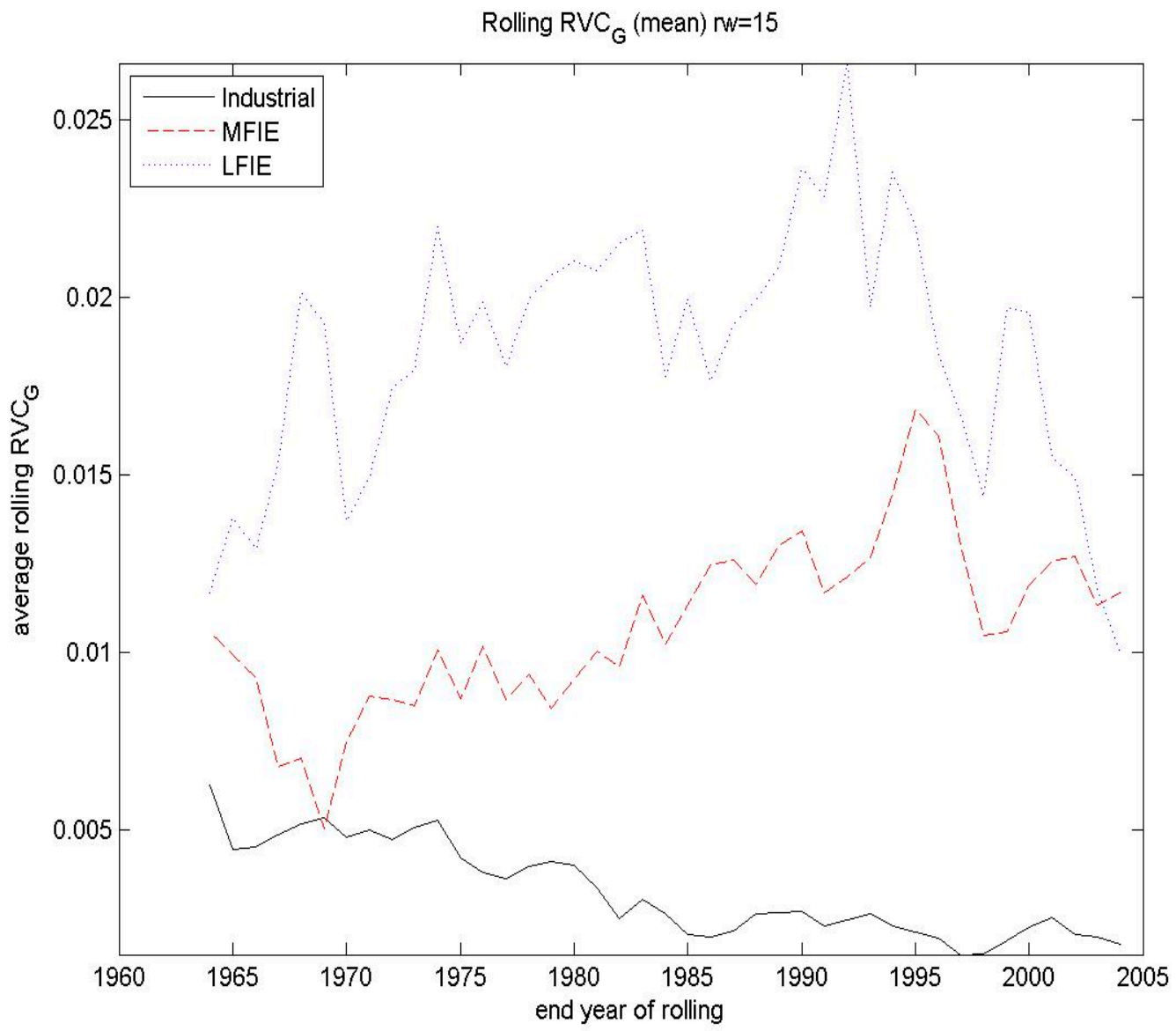




\section{APPENDIX}

\section{Industrial Countries}

Australia (AUS), Austria (AUT), Belgium (BEL), Canada (CAN), Denmark (DNK), Finland (FIN), France (FRA), Germany (GER), Greece (GRC), Ireland (IRL), Italy (ITA), Japan (JPN), Netherlands (NLD), New Zealand (NZL), Norway (NOR), Portugal (PRT), Spain (ESP), Sweden (SWE), Switzerland (CHE), United Kingdom (GBR), United States (USA).

\section{More Financially Integrated Countries:}

Argentina (ARG), Brazil (BRA), Chile (CHL), China (CHN), Colombia (COL), Egypt (EGY), Hong Kong (HKG), India (IND), Indonesia (IDN), Israel (ISR), Korea, Republic of (KOR), Malaysia (MYS), Mexico (MEX), Morocco (MAR), Pakistan (PAK), Peru (PER), Philippines (PHL), Singapore (SGP), South Africa (ZAF), Thailand (THA), Turkey (TUR), Venezuela (VEN).

\section{Less Financially Integrated Countries:}

Algeria (DZA), Bangladesh (BGD), Benin (BEN), Bolivia (BOL), Botswana (BWA), Burkina Faso (BFA), Burundi (BDI), Cameroon (CMR), Costa Rica (CRI), Cote d'Ivoire (CIV), Dominican Republic (DOM), Ecuador (ECU), El Salvador (SLV), Gabon (GAB), Ghana (GHA), Guatemala (GTM), Haiti (HTI), Honduras (HND), Jamaica (JAM), Kenya (KEN), Mauritius (MUS), Nicaragua (NIC), Niger (NER), Nigeria (NGA), Panama (PAN), Papua New Guinea (PNG), Paraguay (PRY), Senegal (SEN), Sri Lanka (LKA), Syria (SYR), Togo (TGO), Tunisia (TUN), Uruguay (URY). 
Industrial Countries

$\begin{array}{cc}\text { Beginning } & \text { End } \\ 1950 & 2004 \\ 1950 & 2004 \\ 1950 & 2004 \\ 1950 & 2004 \\ 1950 & 2004 \\ 1950 & 2004 \\ 1950 & 2004 \\ 1970 & 2004 \\ 1951 & 2004 \\ 1950 & 2004 \\ 1950 & 2004 \\ 1950 & 2004 \\ 1950 & 2004 \\ 1950 & 2004 \\ 1950 & 2004 \\ 1950 & 2004 \\ 1950 & 2004 \\ 1950 & 2004 \\ 1950 & 2004 \\ 1950 & 2004 \\ 1950 & 2004\end{array}$

Australia
Austria
Belgium
Canada
Denmark
Finland
France
Germany
Greece
Ireland
Italy
Japan
Netherlands
New Zealand
Norway
Portugal
Spain
Sweden
Switzerland
United Kingdom
United States

AUS

AUT

BEL

CAN

DNK

FIN

FRA

GER

GRC

IRL

ITA

JPN

NLD

NZL

NOR

PRT

ESP

SWE

CHE

GBR

USA

2004

2004

2004

2004

2004

2004

2004

2004

2004

2004

2004

2004

2004

2004

2004

2004

2004

2004

More Financially Integrated Countries

$\begin{array}{cc}\text { Beginning } & \text { End } \\ 1950 & 2004 \\ 1950 & 2003 \\ 1951 & 2004 \\ 1952 & 2004 \\ 1950 & 2003 \\ 1950 & 2003 \\ 1960 & 2004 \\ 1950 & 2003 \\ 1960 & 2004 \\ 1950 & 2004 \\ 1953 & 2004 \\ 1955 & 2003 \\ 1950 & 2004 \\ 1950 & 2003 \\ 1950 & 2004 \\ 1950 & 2003 \\ 1950 & 2004 \\ 1960 & 2004 \\ 1950 & 2004 \\ 1950 & 2003 \\ 1950 & 2004 \\ 1950 & 2004\end{array}$

ARG

BRA

CHL

$\mathrm{CHN}$

COL

EGY

HKG

IND

IDN

ISR

KOR

MYS

MEX

MAR

PAK

PER

PHL

SGP

ZAF

THA

TUR

VEN
End

2004

2004

2004

2003

2003

2004

2003

2004

2004

2004

2003

2004

2003

2004

2003

2004

2004

2004

2003

2004

2004 
Less Financially Integrated Countries

Beginning End

Algeria
Bangladesh
Benin
Bolivia
Botswana
Burkina Faso
Burundi
Cameroon
Costa Rica
Cote d'Ivoire
Dominican Republic
Ecuador
El Salvador
Gabon
Ghana
Guatemala
Haiti
Honduras
Jamaica
Kenya
Mauritius
Nicaragua
Niger
Nigeria
Panama
Papua New Guinea
Paraguay
Senegal
Sri Lanka
Syria
Togo
Tunisia
Uruguay
Jang

DZA

19602003

BGD $\quad 1972 \quad 2003$

BEN $1959 \quad 2003$

BOL $1950 \quad 2003$

BWA $\quad 1970 \quad 2004$

BFA $\quad 1959 \quad 2004$

BDI $\quad 1960 \quad 2003$

$\begin{array}{lll}\text { CMR } & 1960 & 2003\end{array}$

CRI $1950 \quad 2004$

CIV $\quad 1960 \quad 2003$

DOM $1951 \quad 2003$

ECU $\quad 1951 \quad 2004$

SLV $\quad 1950 \quad 2003$

GAB $\quad 1960 \quad 2004$

GHA $\quad 1955 \quad 2003$

GTM $\quad 1950 \quad 2003$

HTI $1970 \quad 2000$

HND $\quad 1950 \quad 2004$

JAM $1953 \quad 2003$

KEN $\quad 1950 \quad 2003$

MUS $1950 \quad 2004$

NIC $\quad 1950 \quad 2004$

NER $1960 \quad 2004$

NGA $\quad 1950 \quad 2004$

PAN $\quad 1950 \quad 2003$

$\begin{array}{lll}\text { PNG } & 1970 & 2003\end{array}$

PRY $\quad 1951 \quad 2003$

SEN $\quad 1960 \quad 2003$

LKA $\quad 1950 \quad 2003$

SYR $\quad 1960 \quad 2003$

$\begin{array}{lll}\text { TGO } & 1960 & 2004\end{array}$

$\begin{array}{lll}\text { TUN } & 1961 & 2004\end{array}$

URY $\quad 1950 \quad 2004$ 


\section{Data Source and Definitions}

Data is from the Penn World Table Version 6.2 (PWT) by Heston, Summers and Aten. Per capita consumption of a country is $r g d p l$ (real GDP in international \$ in 2000 constant prices) times $k c$ (consumption share of rgdpl); population is pop.

\section{World Per Capita Consumption Index:}

We need to calculate the index because missing data prohibit us from using a simple aggregation of countries' aggregate consumption and population to obtain world per capita consumption.

Step 1: create a country's aggregate consumption by multiplying per capita consumption ( $r g d p l$ $\mathrm{x} k c$ ) by population ( $p o p$ ) using data from PWT.

Step 2: create world consumption and population for years $t$ and $t+1$ by summing up all countries after eliminating those with missing data in either year.

Step 3: calculate world consumption growth rates and world population growth rates for year $\mathrm{t}+1$ by taking the first difference of logs.

Step 4: repeat steps 2 and 3 to obtain growth rates for 1951-2004.

Step 5: use growth rates to create indices of world consumption and world population and then create a world per capita consumption index.

Note that since the level does not matter for the risk-sharing measure, the index is a sufficient statistic. 


\section{REFERENCES}

Aguiar, Mark, and Gita Gopinath, 2007, "Emerging Market Business Cycles: The Cycle is the Trend," Journal of Political Economy, February 2007, Vol. 115, No. 1, pp.69102.

Artis, Michael, and Mathias Hoffmann, 2008, "Financial Globalization, International Business Cycles, and Consumption Risk Sharing," Scandinavian Journal of Economics, Vol.110, No. 3, pp. 447-71.

Artis, Michael, and Mathias Hoffmann, 2007, "Declining Home Bias and the Increase in International Risk Sharing: Lessons from European Integration," in Lars Jonung, Christoph Walker and Max Watson (eds.) Building the Financial Foundations of the Euro:Experiences and Challenges.

Asdrubali, Pierfederico, Bent E. Sørensen, and Oved Yosha, 2007, "Channels of Interstate Risk Sharing: United States 1963-1990," The Quarterly Journal of Economics, Vol. 111, No. 4, pp. 1081-110.

Bai, Yan and Jing Zhang, 2005, "Financial Integration and International Risk Sharing," Unpublished, Arizona State University and University of Michigan.

Becker, S. O., and Mathias Hoffmann, 2006, "Intra- and International Risk Sharing in the Short-Run and the Long-Run," European Economic Review, Vol. 50, pp. 777-806.

Canova, Fabio, and Morten Ravn, 1996, "International Consumption Risk Sharing," International Economic Review, Vol. 37, No. 3, pp. 573-601.

Corcoran, Aidan, 2007, "International Financial Integration and Consumption Risk Sharing," mimeo, Trinity College Dublin.

Devereux, Michael B., Allan W. Gregory, and Gregor W. Smith, 1992, "Realistic CrossCountry Consumption Correlations in a Two-Country Real Business Cycle Model," Journal of International Money and Finance, Vol. 11, pp. 3-16.

Devereux, Michael B., and Makoto Saito, 1997, "Growth and Risk-Sharing with Incomplete International Assets Markets," Journal of International Economics, Vol. 42, pp. 45381.

Heathcote, Jonathan, and Fabrizio Perri, 2003, "Why Has the U.S. Economy Become Less Correlated with the Rest of the World?" American Economic Review, Vol. 93, No. 2, pp. 63-69.

— 2004, "Financial Globalization and Real Regionalization," Journal of Economic Theory, Vol. 119, No. 1, pp. 207-43. 
Heston, Alan, Robert Summers, and Bettina Aten, 2006, Penn World Table Version 6.2, Center for International Comparisons of Production, Income and Prices at the University of Pennsylvania, September 2006.

Kalemli-Ozcan, Sebnem, Bent Sorensen, and Oved Yosha, 2003, "Risk Sharing and Industrial Specialization: Regional and International Evidence," American Economic Review," Vol. 93, No. 3, pp. 903-18.

Kose, M. Ayhan, Eswar Prasad, and Marco Terrones, 2003a, "How Does Globalization Affect the Synchronization of Business Cycles?" American Economic Review, Vol. 93, No. 2, pp. 57-63.

— , 2003b, "Financial Integration and Macroeconomic Volatility," IMF Working Paper 03/50, March, IMF Staff Papers, Vol. 50, No. 1.

_ 2007, "How Does Financial Globalization Affect Risk-Sharing? Patterns and Channels," IMF Working Paper.

Kose, M. Ayhan, Eswar Prasad, Kenneth Rogoff, Shang-Jin Wei, 2006, "Financial Globalization: A Reappraisal,” IMF Working Paper 06/189.

Lewis, Karen, 1996, "What Can Explain the Apparent lack of International Consumption Risk Sharing?” Journal of Political Economy, Vol. 104, No. 2, pp. 267-97.

Lucas, Robert, 1987, Models of Business Cycles, Oxford \& New York: Blackwell.

Matsumoto, Akito, 2007, "The Role of Nonseparable Utility and Nontradeables in International Business Cycles and Portfolio Choice," International Monetary Fund Working Paper No. 07/163.

Obstfeld, Maurice, 1986, "Capital Mobility in the World Economy: Theory and Measurement," in Karl Brunner and Allan Meltzer (eds), The National Bureau Method, International Capital Mobility, and Other Essays, Amsterdam: NorthHolland. (Carnegie-Rochester Conference Series on Public Policy, Vol. 24, a supplement to the Journal of Monetary Economics, Spring).

— 1994a, "Risk-Taking, Global Diversification, and Growth," American Economic Review, Vol. 84, No. 5, December, pp. 1310-329.

—_ 1994b, “Are Industrial-Country Consumption Risks Globally Diversified?” in Leonardo Leiderman and Assaf Razin (eds), Capital Mobility: The Impact on Consumption, Investment and Growth, Cambridge: Cambridge University Press.

_ nderstanding Interdependence: The Macroeconomics of the Open Economy, Princeton: Princeton University Press, 1995. 
Pakko, Michael, 1998, "Characterizing Cross-Country Consumption Correlations," Review of Economics and Statistics, Vol. 80, No. 1, pp. 169-74.

Bent Sørensen, Yi-Tsung Wuc, Oved Yoshad, and Yu Zhuc, 2007, "Home Bias and International Risk Sharing: Twin Puzzles Separated at Birth" Journal of International Money and Finance, Vol. 26, No. 4, pp. 587-605.

van Wincoop, Eric, 1999, "How Big are Potential Gains from International Risksharing?" Journal of International Economics, Vol. 47, No. 1, 1999, pp. 109-35. 